\title{
Statistical analysis of storm-time near-Earth current systems
}

\author{
M. W. Liemohn ${ }^{1}$, R. M. Katus ${ }^{1,2}$, and R. Ilie ${ }^{1}$ \\ ${ }^{1}$ Atmospheric, Oceanic, and Space Sciences Department, University of Michigan, Ann Arbor, MI USA \\ ${ }^{2}$ Department of Physics and Astronomy, West Virginia University, Morgantown, WV USA \\ Correspondence to: M. W. Liemohn (liemohn@umich.edu) \\ Received: 13 April 2015 - Revised: 3 July 2015 - Accepted: 13 July 2015 - Published: 7 August 2015
}

\begin{abstract}
Currents from the Hot Electron and Ion Drift Integrator (HEIDI) inner magnetospheric model results for all of the 90 intense storms (disturbance storm-time (Dst) minimum <-100 nT) from solar cycle 23 (1996-2005) are calculated, presented, and analyzed. We have categorized these currents into the various systems that exist in near-Earth space, specifically the eastward and westward symmetric ring current, the partial ring current, the banana current, and the tail current. The current results from each run set are combined by a normalized superposed epoch analysis technique that scales the timeline of each phase of each storm before summing the results. It is found that there is a systematic ordering to the current systems, with the asymmetric current systems peaking during storm main phase (tail current rising first, then the banana current, followed by the partial ring current) and the symmetric current systems peaking during the early recovery phase (westward and eastward symmetric ring current having simultaneous maxima). The median and mean peak amplitudes for the current systems ranged from 1 to $3 \mathrm{MA}$, depending on the setup configuration used in HEIDI, except for the eastward symmetric ring current, for which the mean never exceeded 0.3 MA for any HEIDI setup. The selfconsistent electric field description in HEIDI yielded larger tail and banana currents than the Volland-Stern electric field, while the partial and symmetric ring currents had similar peak values between the two applied electric field models.
\end{abstract}

Keywords. Magnetospheric physics (current systems; storms and substorms) - space plasma physics (numerical simulation studies)

\section{Introduction}

Modeling studies have long been used to understand the dynamics of storm-time current systems in the inner magnetosphere and have shown that there is substantial variability from storm to storm in the location, timing, and intensity of each current system. For instance, Ganushkina et al. (2002, 2004) modified the Tsyganenko (1989) empirical field model to best fit data for particular storm events, showing that the inner magnetospheric current systems become highly distorted from their average state. Similarly, Kubyshkina et al. (2008) also used this model to show how different sawtooth event current systems are from typical magnetospheric conditions. Depending on the pressure profile at the inner edge of the plasma sheet and in the inner magnetosphere, the pressure peak could be located quite far out from Earth (i.e., beyond geosynchronous orbit) resulting in an eastward current system where one typically thinks the westward current should be located (e.g., Mauk and Zanetti, 1987; Antonova and Ganushkina, 2000; Antonova et al., 2013). Tsyganenko et al. (2003) used a storm-specific magnetic field empirical model for superstorm-class events, producing very large perturbations in the evening sector due to an exceptionally strong main phase partial ring current. Asikainen et al. (2010) created a new empirical model like the Burton et al. (1975) prediction technique, but one that separates the contribution of the ring, tail, and magnetopause currents, determining that most of the disturbance storm-time (Dst) perturbation is from the component designated as ring current. Interestingly, Ganushkina et al. (2012b) showed that the summation of currents from empirical models yield different patterns for the usual definition of the current systems; that is, current designated as tail current in the empirical model became partial ring current in the integrated current analysis. More recently, Dubyagin et al. (2013a, b) investigated the presence 
of an intense yet thin current layer in the duskside near-Earth magnetosphere during magnetic storms, determining that it is an unusual partial ring current confined near the magnetic equator.

First-principles drift physics models have also been used to analyze the current systems in the inner and near-Earth nightside magnetosphere. Liemohn et al. (2001b), using the inner magnetosphere drift physics model now called the Hot Electron and Ion Drift Integrator (HEIDI), examined currents in several magnetic storm events and concluded that nearly all of the current is asymmetric during the main phase. Zhang et al. (2009) used the Rice Convection Model (RCM) to show that the simulated field-aligned currents during an injection event matched the observations very well. Buzulukova et al. (2010) used the Space Weather Modeling Framework (SWMF) with the inclusion of an inner magnetosphere model to show that realistic region 2 currents are needed to match the observations for the selected storm interval. Several different codes were used by Ganushkina et al. (2010) to assess the timing and intensity of current systems in the nightside magnetosphere, showing the transition from tail current dominance in the perturbation to ring current dominance later in the selected storms. Liemohn et al. (2011b, 2013b) are two studies using the SWMF to examine events driven by a coronal mass ejection and co-rotating interaction region, respectively, finding very similar patterns to the timing and intensity of the current system progression. Liemohn et al. (2013a) quantified the breakdown of the total cross-field current into specific current systems, showing that, at least within geosynchronous orbit, the partial ring current is often dominant during the main phase.

All of these studies, however, examine one or just a few specific substorm or storm events. This is because it is difficult (i.e., computationally expensive) to run a first-principles model for many different storm intervals, and the different timing of storm phases further obscures the analysis of the results. Liemohn and Jazowski (2008) presented and analyzed the results from HEIDI simulations of 90 different intense storms. That study only considered a single setup configuration of the HEIDI model, and several follow-on studies continued the analysis of these 90 intense storms for other boundary condition applications, data-model comparison techniques, and categorization of the solar wind driving conditions (Liemohn et al., 2010; Liemohn and Katus, 2012; Katus et al., 2015). Using the superposed epoch storm time normalization method of Katus et al. (2013) and the current system identification technique developed by Liemohn et al. (2013a), this set of model results is ideal for statistically assessing the behavior of inner magnetospheric current systems, examining the timing and intensity of these currents as a function of epoch time relative to the storm start, peak, and end. The study below presents this analysis, addressing the question of how the inner magnetospheric current systems behave on average during intense magnetic storm events.

\section{Approach}

Before showing the results and discussing the findings of the study, a synopsis is given here about the numerical approach, the setup configuration for the simulations, and the superposed epoch determination.

\subsection{HEIDI intense storm database}

HEIDI solves the gyration and bounce-averaged kinetic equation for phase space density of hot $(10 \mathrm{eV}-400 \mathrm{keV})$ charged particles in near-Earth space. This drift physics model was originally written 2 decades ago (Fok et al., 1993; Jordanova et al., 1994) and the specific version of the code used for this study is described in detail by Liemohn et al. (1999, 2001a, 2004). It is not a particle-tracking code, but rather it solves fluid-like advection and diffusion equations across a two-dimensional real space grid (equatorial plane inside of geosynchronous orbit) and a two-dimensional velocity space grid (energy and equatorial pitch angle). The typical time step in HEIDI is between 5 and $20 \mathrm{~s}$.

The storm database was created by Zhang et al. (2007a, b), who determined the solar and heliospheric driver for every intense (Dst minimum < - $100 \mathrm{nT}$ ) magnetic storm during the last solar cycle (years 1996-2005, inclusive). The original storm list of 88 intense storms was expanded to 90 for this study; the two additional storms are those of April 17 and 19, 2002. These two storm days are adjacent to two other days already in the list (18 and 20 April 2002), but they have their own Dst minima and are driven by distinct aspects of the chain of solar wind disturbances moving past Earth during this interval. Therefore, these four days are designated as four different storm events in our database.

The HEIDI "runset" database of these storm intervals was first described by Liemohn and Jazowski (2008), for just one setup configuration, categorizing the events according to their solar wind driving structure. Liemohn et al. (2010) then presented an initial analysis of several more run sets with different plasma and electric field boundary conditions, determining that the response of the inner magnetosphere was fundamentally different between storms driven by interplanetary coronal mass ejections (ICMEs) and co-rotating interaction regions (CIRs). Liemohn and Katus (2012) then expanded this data-model comparison by considering the entire storm timeline, rather than just the storm peak values, with a superposed epoch analysis of the model results. Most recently, Katus et al. (2015) conducted a normalized superposed epoch analysis of the results with additional statistical techniques in the data-model comparison to further quantify which simulation runset best describes the inner magnetosphere during various solar wind driving conditions. Note that all of these simulations were conducted with a static dipole magnetic field, a limitation of the results that will be discussed later in the section on caveats. A few key figures from each 
simulation in the HEIDI runset database are available at the Virtual Model Repository (http://vmr.engin.umich.edu/).

The boundary conditions and electric fields for the four runsets to be discussed in this study are given in Table 1 . Two plasma boundary conditions and two electric field descriptions are used. The "event-specific data" uses the fluxes from the magnetospheric plasma analyzer (MPA) (Bame et al., 1993) and synchronous orbiting particle analyzer (SOPA) (Belian et al., 1992) instruments on the geosynchronously orbiting satellites operated by the Los Alamos National Laboratory (LANL). The data from the satellite with the highest ion density that is located within $\pm 4 \mathrm{~h}$ of local midnight is concatenated into a high-time-resolution outer boundary condition for HEIDI, applied uniformly at all local times. The "LANL reanalysis" boundary condition uses the database of density and temperature moments created by O'Brien and Lemon (2007). This database is divided into hourly bins in both local time (LT) and universal time (UT). If a LANL satellite exists in that LT-UT bin, then that data is averaged. If not, then that bin is filled by data from other times when a LANL satellite was located within at that LT hour and for solar and geophysical conditions that are similar to those at the specific UT of interest. These other data were then weighted according to the similarity of the driving conditions and averaged plasma moments were created for that bin. The first electric field description is the Volland-Stern analytical model (Volland, 1973; Stern, 1975) with a shielding factor of 2 and an activity dependence specified by the $3 \mathrm{~h} \mathrm{Kp}$ index (Maynard and Chen, 1975). The second electric field description is a self-consistent electric field model, in which the plasma pressures calculated by HEIDI are used to determine currents (Liemohn et al., 2001b) that are applied as source/sink terms in an ionospheric electric potential solver (Ridley and Liemohn, 2002). These potentials are mapped to the equatorial plane and used within HEIDI for the ExB drift during the next time step (Liemohn et al., 2004). The ionospheric conductance in the potential solver is defined as a smooth oval that varies in intensity and location according to the peak field-aligned current, as determined by Ridley et al. (2001, 2004). The specific parameter setting used for these simulations are the "nominal settings" from Liemohn et al. $(2005,2006)$.

\subsection{Near-Earth currents}

The current density in the simulation domain is determined from the plasma pressure (e.g., Parker, 1957; Lui et al., 1987),

$\mathbf{J}_{\perp}=\frac{\mathbf{B}}{B^{2}} \times\left[\nabla P_{\perp}+\left(P_{||}-P_{\perp}\right) \frac{\nabla B}{B}\right]$,

where $P_{\|}$and $P_{\perp}$ are integrated quantities from the local velocity space distribution (e.g., Lemaire and Scherer, 1971;
Table 1. Runset Configuration Definitions.

\begin{tabular}{lll}
\hline Runset no. & Electric field & $\begin{array}{l}\text { Plasma boundary } \\
\text { condition }\end{array}$ \\
\hline No. 1 & Volland-Stern & Event-specific data \\
No. 2 & Self-consistent & Event-specific data \\
No. 3 & Volland-Stern & LANL reanalysis \\
No. 4 & Self-consistent & LANL reanalysis \\
\hline
\end{tabular}

Chiu and Schulz, 1978; Liemohn and Khazanov, 1998),

$P_{\perp}=\pi \int f(E, \alpha) \sqrt{\frac{2 E}{m}} \sin ^{3} \alpha \mathrm{d} E \mathrm{~d} \alpha$,

$P_{\|}=2 \pi \int f(E, \alpha) \sqrt{\frac{2 E}{m}} \cos ^{2} \alpha \sin \alpha \mathrm{d} E \mathrm{~d} \alpha$.

In Eq. (2), $f$ is the phase space distribution and $E$ and $\alpha$ are the energy and local pitch angle of the particle, where the latter is found by mapping the equatorial pitch angle along the field line according to the first adiabatic invariant. Equation (1) is applied everywhere along a field line to define a perpendicular current density everywhere in the simulation domain, not only in the equatorial plane but also along the field lines.

The divergence of the perpendicular current density is used to find the field-aligned current density (e.g., Vasyliunas, 1970; Birmingham, 1992),

$\nabla \cdot \mathbf{J}_{\perp}=\mathbf{B} \cdot \nabla\left(\frac{J_{\|}}{B}\right)$.

Equation (3) is numerically integrated along the field line to yield a current density flowing into or out of the ionosphere (e.g., Liemohn et al., 2001b; Ridley and Liemohn, 2002),

$$
\begin{aligned}
J_{\|}\left(\boldsymbol{r}_{\text {iono }}\right)= & \frac{1}{A_{\|}\left(\boldsymbol{r}_{\text {iono }}\right)} \sum_{k=k_{\text {eq }}}^{k_{\text {iono }}} \\
& {\left[\sum_{i=\perp \text { faces }} A_{i, k}(k) \boldsymbol{J}_{\perp, i, k}(k) \cdot \hat{\boldsymbol{n}}_{i, k}(k)\right], }
\end{aligned}
$$

where $A_{\|}$is the cross-sectional area of the flux tube at the ionosphere, $A_{i, k}$ are the area of the faces with neighboring cells at a location $k$ along the field line with normal vector $\boldsymbol{n}_{i, k}$, and $\boldsymbol{r}_{\text {iono }}$ is the vector location of the magnetic field line footpoint at $120 \mathrm{~km}$ altitude.

To calculate current system magnitudes from the HEIDI simulations, these local current densities must be integrated with the following methodology that isolates current loops according to their closure path. Specifically, the local current densities from Eqs. (1) and (4) are integrated to yield total current values. The values from Eq. (1) are separated into their azimuthal and radial components. Each of these components is then separated into eastward-westward and inwardoutward current densities. The eastward and westward current densities are separately integrated over each meridional 
plane to yield directional azimuthal current values as a function of local time. Similarly, the inward and outward current densities are separately integrated over each radial shell to yield directional radial current values as a function of $\mathrm{L}$ shell. In addition, the field-aligned current densities from Eq. (4) are categorized by their sign, which are separately integrated to yield total field-aligned current values into and out of the ionosphere.

There are five current systems to define for this study: partial ring current, banana current, tail current, westward symmetric ring current, and eastward symmetric ring current. Each one has a special definition for calculating its magnitude from the HEIDI simulation results. Figure 1a shows a schematic of these five near-Earth nightside current systems. Of course, this is only an idealized wire diagram representation and the real spatial locations are distributed regions of current flow that can be quite complicated (see, e.g., Liemohn et al., 2011b, 2013b).

The partial ring current is specified here as inner magnetospheric current that closes through field-aligned currents and through the ionosphere. It is defined as the larger of the total current flowing into or out of the ionosphere (summed separately). The larger value is used because some of the fieldaligned current could be located outside of the simulation domain, and therefore even the use of the larger of the two is a minimum value for the partial ring current intensity.

The banana current is defined as the current loop that encircles each pressure peak within the simulation domain, and is calculated following the procedure defined by Liemohn et al. (2013a). Essentially, it is the sum of the differences between each pair of relative maxima and minima in eastward azimuthal current.

The tail current is defined as current that flows westward across the plasma sheet and then closes via magnetopause currents around the lobes. Defining it from the HEIDI simulations, it is calculated as the smaller of the total current flowing radially into or out of the outer simulation domain. The smaller value is used because the imbalance means that some of the current through the boundary closes via another path (such as through the ionosphere).

The symmetric ring current is defined as the current loop that encircles the Earth. Therefore, the westward symmetric ring current is defined as the minimum (in local time) westward azimuthal current, and the eastward symmetric ring current is defined as the minimum of the eastward azimuthal current.

All of these current system definitions are lower limits to the real values. This is because of the fixed spatial domain of the HEIDI simulations to be considered for this study. A portion of the current for these systems (any of the abovedefined current system) could be located either inside the inner boundary (i.e., closer to Earth than $L=1.875$ ) or outside of the outer boundary (beyond $L=6.625$ ). This is especially true of the tail current definition, but is also true for the other four current systems. Even the eastward symmetric ring cur- rent could be underestimated if the peak of the plasma pressure is close to Earth (near storm peak) or beyond geosynchronous (prestorm or late recovery phases). Furthermore, the current defined as "tail" for this study may, in fact, not be the current that closes on the nightside magnetopause, because it is unknown how the radial current through the outer simulation boundary eventually closes. This means that this current could actually be the partial ring, symmetric ring, or banana current.

\subsection{Normalized superposed epoch analysis technique}

Previous studies have analyzed the HEIDI storm runset database by superposing the results from the individual storms and examining the resulting statistical data-model comparisons. Liemohn et al. (2010) considered times near the storm peak in their data-model comparisons, while Liemohn and Katus (2012) extended this analysis to all times throughout a geomagnetic storm sequence by superposing the storm time lines with respect to the observed Dst minimum.

A single reference time within a storm is not sufficient to accurately capture all of the physical features in the averaged data sets. Ilie et al. (2008) found that the choice of reference time during a geomagnetic storm for a superposed epoch analysis can impact the resulting averages and the scientific conclusions drawn from the results. The duration of the main phase can vary dramatically from storm to storm, and thus a superposition at the storm peak will smear out the averaging of the beginning of the storm interval. Thus, a normalized timeline with multiple references is desirable. Katus et al. (2015) went another step further in the analysis of the HEIDI solar cycle runsets by normalizing the length of each phase during each storm before superposing and averaging the results. They followed the method of Katus et al. (2013) to identify key reference times in each of the storm intervals, defining four phases within each event: a pre-storm phase, an initial phase, a main phase, and a recovery phase. The average length for each of these phases was calculated and the specific time interval from each event's phase was expanded or contracted to match this average length for that phase. The result is that all of the storms are now on the same normalized timeline, with the duration equal to the mean length of the storms within the database.

Katus et al. (2015) applied this type of normalized superposed epoch analysis technique to these runsets of the HEIDI model, focusing on the data-model comparison of the results and identification of which runset most accurately describes the state of the inner magnetosphere for various solar wind driving conditions. Following the same runset numbering scheme as used here, they concluded that Runset no. 1 was best for CIR-driven intense storms while Runset no. 2 was best for ICME-driven intense storms. It was determined that Runset no. 2, with the event-specific LANL outer boundary condition with the self-consistent electric field, was the best 
(a) Schematic of near-Earth nightside current systems

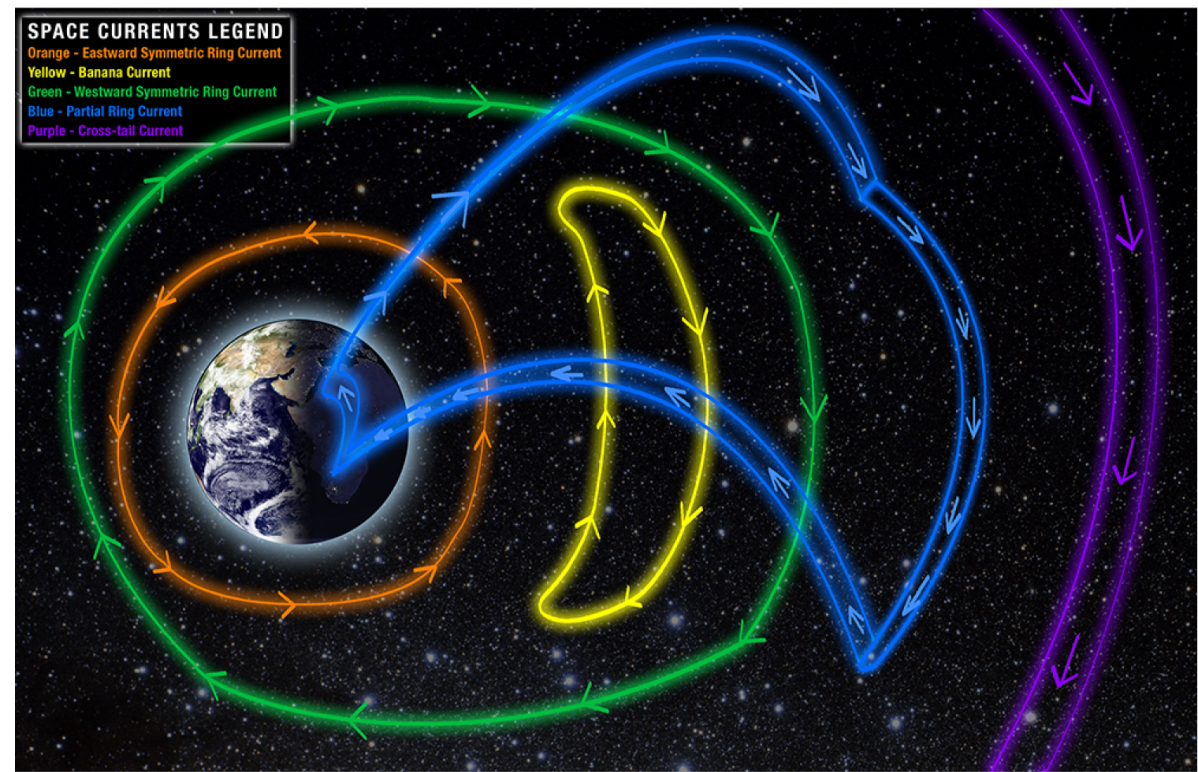

(b) Relationship of partial ring current with plasma pressure and flow

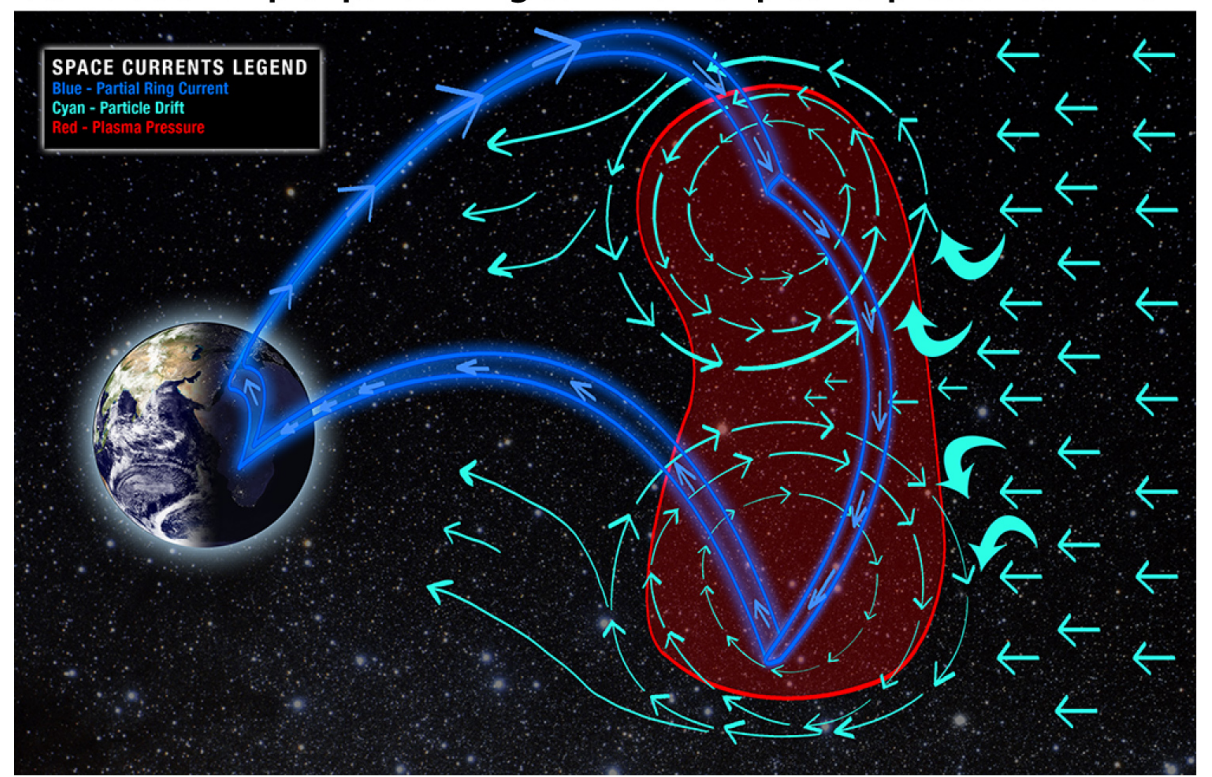

Figure 1. (a) Schematic of near-Earth nightside current systems, showing the eastward symmetric ring current in orange, the banana current in yellow, the westward symmetric ring current in green, the partial ring current in blue, and the cross-tail current in purple. (b) Schematic of the relationship of the partial ring current (in blue) to a localized plasma pressure peak (in red) and the plasma flow directions (cyan). Image from S. Wetmore and M. Liemohn.

performing model setup in an overall sense, taking into consideration the variety of driving conditions and storm phases.

In the present study, the same normalized-timeline superposed epoch analysis of Katus et al. (2015) will be applied. For this study, the examination focuses on the resulting current systems from the HEIDI simulation results to assess the timing and intensity of each current system as a function of storm phase. This study does not focus on data-model comparisons to determine the best fit model setup to a particular set of observations, but rather focuses on the timing and intensity of each current system and the influence of model setup on these properties of the near-Earth current systems.

\section{Results}

Initially, an example storm interval is presented to identify the key features of the pressure and current systems during 


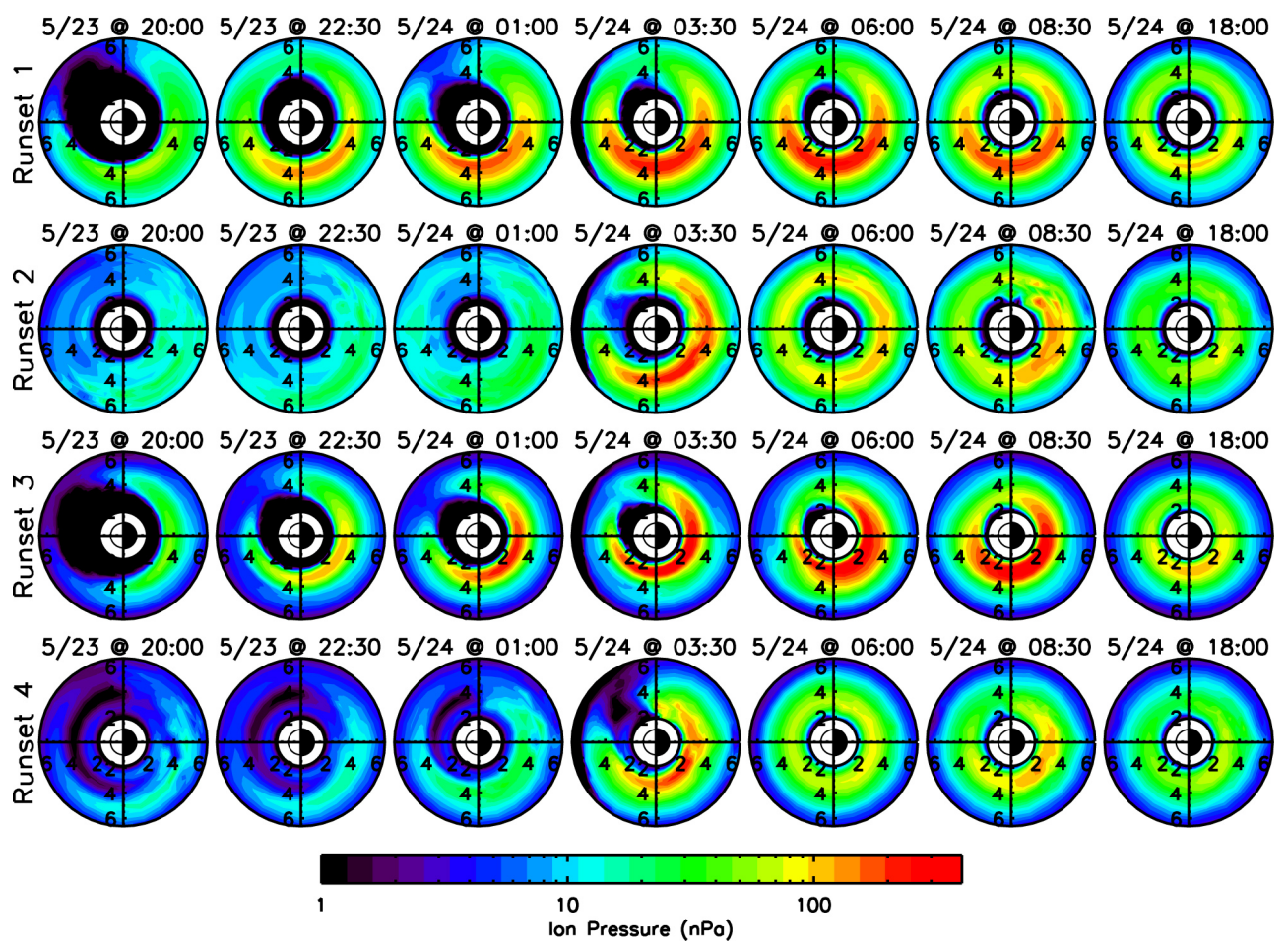

Figure 2. Equatorial plane plasma pressure from the four runsets of HEIDI (each row) for the 24 May 2000 storm. The times that were selected span from the beginning of the main phase (leftmost column) to the late recovery phase (rightmost column), with the simulated peak of the storm at or near the third (Runsets no. 2 and no. 4) or fourth (Runsets no. 1 and no. 3) columns. The view is from over the North Pole with the Earth in the middle, the Sun to the left, and distances in Earth radii.

each phase. This is followed by a statistical analysis of the normalized superposed epoch averages.

\subsection{Case study: 24 May 2000}

This storm was driven by a pair of interplanetary coronal mass ejections (ICME) that reached the Earth's magnetopause on 23 May 2000 (Zhang et al., 2007a, b). Both ICMEs had north then south interplanetary magnetic field (IMF) time series, so the strong activity within the magnetosphere does not start until late on 23 May (about $\sim$ 17:00 UT), reaching a peak early on 24 May. The hourly Dst index and SYM-H, its one-minute counterpart index, both have a sharp and rapid fall from $+20 \mathrm{nT}$ to roughly $-150 \mathrm{nT}$ from 02:00 to 04:00 UT, followed by a double peak of similar magnitude occurring at $\sim$ 09:00 UT. The auroral electrojet (AE) index has several spikes above $1000 \mathrm{nT}$ during the main phase of the storm. This storm was, coincidentally, the first observed during the IMAGE spacecraft mission. Details of the storm interval were presented by Brandt et al. (2002).

Figure 2 shows equatorial plane hot ion pressures $\left(\mathrm{H}^{+}\right.$and $\mathrm{O}^{+}$) from the four runsets of HEIDI (rows) at seven times during the storm interval (columns). The times that were selected range from early in the main phase (left column) through the storm peak (center two columns) to late in the recovery phase (right column). The view is over the North Pole with distances given in Earth radii, showing the spatial domain of HEIDI used in these simulations.

It is seen that Runsets no. 1 and no. 3, the runs with the Volland-Stern electric field, produce very large plasma pressures in the inner magnetosphere, contained within a single pressure crescent peaking in the evening sector. Runsets no. 2 and no. 4, the simulations with a self-consistent electric field, produced smaller peak plasma pressures that show considerable small-scale structure with several localized peaks. The feedback on the electric potential from the current systems calculated from the HEIDI simulation results is the reason for the small-scale structure, as has been discussed before (see Liemohn et al., 2004, 2005; Liemohn and Brandt, 2005). Despite these differences, the overall trend is the same for all four runsets: a highly asymmetric pressure distribution throughout the main phase of the storm that transitions into a more symmetric ring of pressure by the late recovery phase. All runsets still show a pressure asymmetry in the final column.

Figure 3 presents the calculated azimuthal current densities in the equatorial plane from the four HEIDI runsets (rows) for the same seven times (columns). The blue-purple colors are westward current and the yellow-red colors indicate eastward current. As with the pressure in Fig. 1, it is seen 


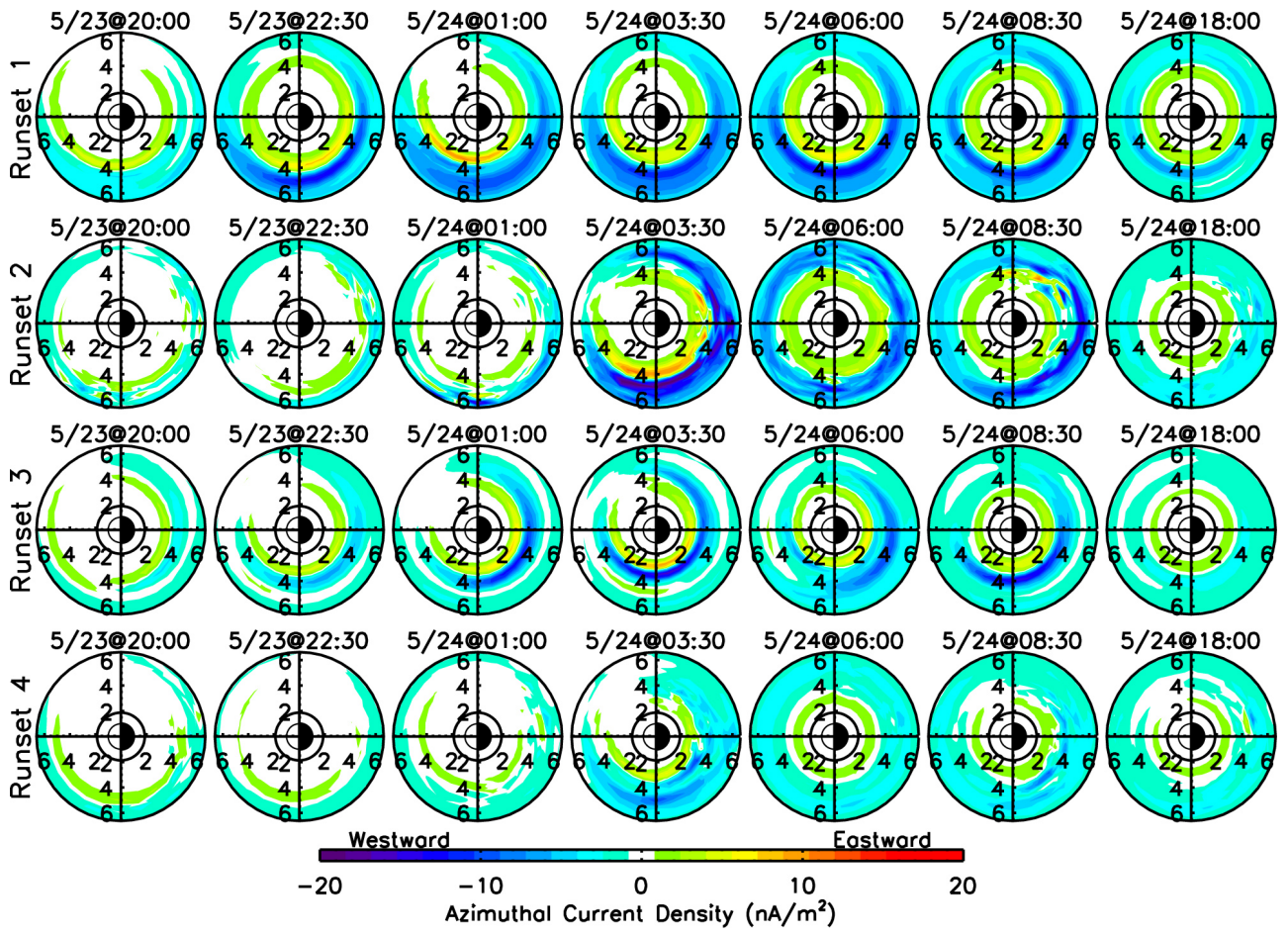

Figure 3. Equatorial plane azimuthal current density from the four runsets of HEIDI (each row) for the 24 May 2000 storm. The times that were selected span from the beginning of the main phase (leftmost column) to the late recovery phase (rightmost column), with the simulated peak of the storm at or near the third (Runsets no. 2 and no. 4 ) or fourth (Runsets no. 1 and no. 3) columns. The view is from over the North Pole with the Earth in the middle, the Sun to the left, and distances in Earth radii.

that the currents for Runsets no. 1 and no. 3 are smoother than those for Runsets no. 2 and no. 4. Because these current density values are shown on a linear scale, it is easier to compare peak magnitudes than in Fig. 2. Runset no. 2 has the largest azimuthal current densities, followed by Runset no. 1, then Runset no. 3, and finally Runset no. 4. It is also readily seen that the Volland-Stern electric field is capable of producing multiple peaks in pressure and therefore in the westward azimuthal current density, as evidenced by the second ring/peak of blue in the plots for Runsets no. 1 and no. 3. As with the pressure, however, the trend through the storm interval is the same for all four runsets: the current is highly asymmetric at the beginning of the storm, intensifies but remains highly asymmetric throughout the main phase, and finally transitions to a more symmetric azimuthal current pattern by the late recovery phase.

To quantitatively compare the current system timing and intensities from the four configurations of HEIDI for this storm interval, the current system definitions listed above were applied to the simulation results. Figure 4 shows the outcome of this calculation, presenting the current system magnitudes throughout the 4-day simulation interval (00:00 UT on 23 May to 00:00 UT on 27 May). Keep in mind that the storm main phase begins around 17:00 UT on 23 May and reaches its maximum between 03:00 and 06:00 UT on 24 May, depending on the simulation.
Again, there is a systematic difference between the simulations with the Volland-Stern electric field (Runsets no. 1 and no. 3) and those with the self-consistent electric field (Runsets no. 2 and no. 4), with the former yielding smoother time series for the current system magnitudes than the latter. In addition, for Runsets no. 1 and no. 3, there is a clear transition from the "asymmetric" current systems (tail, banana, and partial ring currents) to the "symmetric" current systems (especially to the westward symmetric ring current). This transition is somewhat visible in the results for Runsets no. 2 and no. 4, with the symmetric current systems rapidly rising from near zero up to their peak values early on 24 May, but the timing and clarity of the changeover from asymmetric to symmetric current system dominance is far more ambiguous.

Finally, there appears to be a difference in the magnitudes between two plasma boundary conditions applied. The eventspecific LANL values (Runsets no. 1 and no. 2) yield systematically larger currents than the reanalyzed LANL values (Runsets no. 3 and no. 4). This is not necessarily expected because the event-specific inputs are essentially a subset of the reanalysis values. Even though the reanalyzed values are hourly averages, Liemohn et al. (2011a) found that averaging across such a window had very little effect on the resulting storm intensity from the HEIDI model. The reason, as seen and discussed in Katus et al. (2015), is that the reanalysis values contain additional moments that slightly lower 

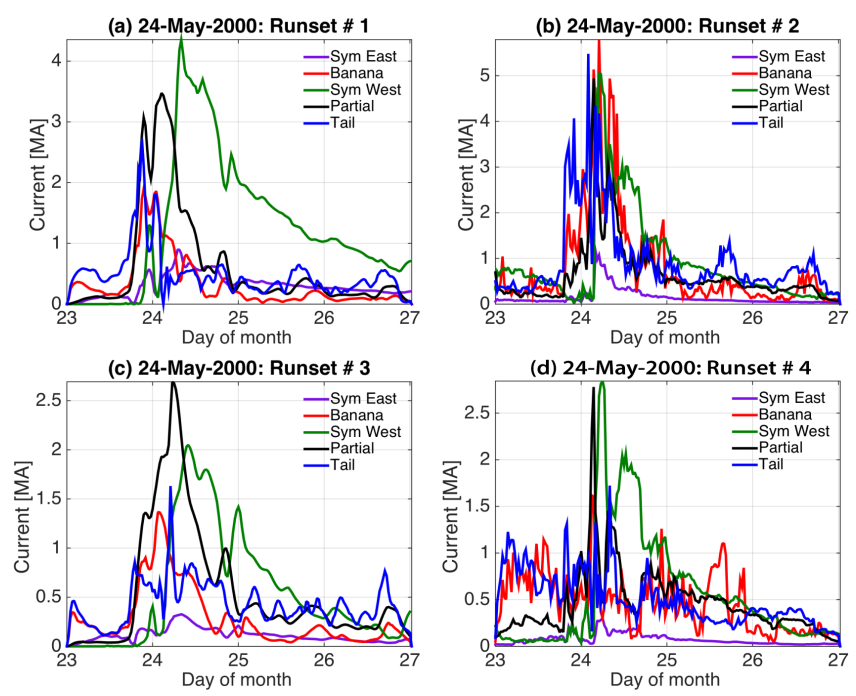

Figure 4. Current system calculations from the four HEIDI runsets (each panel) for the 24 May 2000 storm interval. Each colored line is the time series value for a different current system from that simulation.

the density and raise the temperature of the plasma boundary condition relative to the event-specific values. Each of these changes effectively lowers the intensity of the resulting current systems within the HEIDI simulation domain.

\subsection{Statistical analysis}

Moving on to the statistical analysis, the results from each individual storm were processed and then combined. Specifically, the durations for each phase of each storm were expanded or contracted to match the average length for that phase to normalize the timeline before superposing the events together.

Figure 5 presents the total energy content of all hot ion species within the HEIDI simulation domain, converted to a magnetic perturbation by applying the DesslerParker-Sckopke equation (Dessler and Parker, 1959; Sckopke, 1966),

DPS $^{*}=-3.98 \times 10^{-30} E_{\mathrm{RC}}[\mathrm{keV}]$,

which is a quantity somewhat analogous to Dst*, the modified version of the Dst index after the removal of magnetopause currents, quiet time offset, and induced currents within the Earth. In each plot, the color background shows a histogram of the number of HEIDI DPS* entries into each $30 \mathrm{~min}$ by $2 \mathrm{nT}$ bin (100 evenly spaced bins over the $y$ axis). Also drawn in each panel is a white and purple curve through the colored region. These two lines are the median and mean DPS* values for that epoch time, respectively. The four purple vertical lines indicate the boundaries between the storm phases used in the normalization of the timeline.
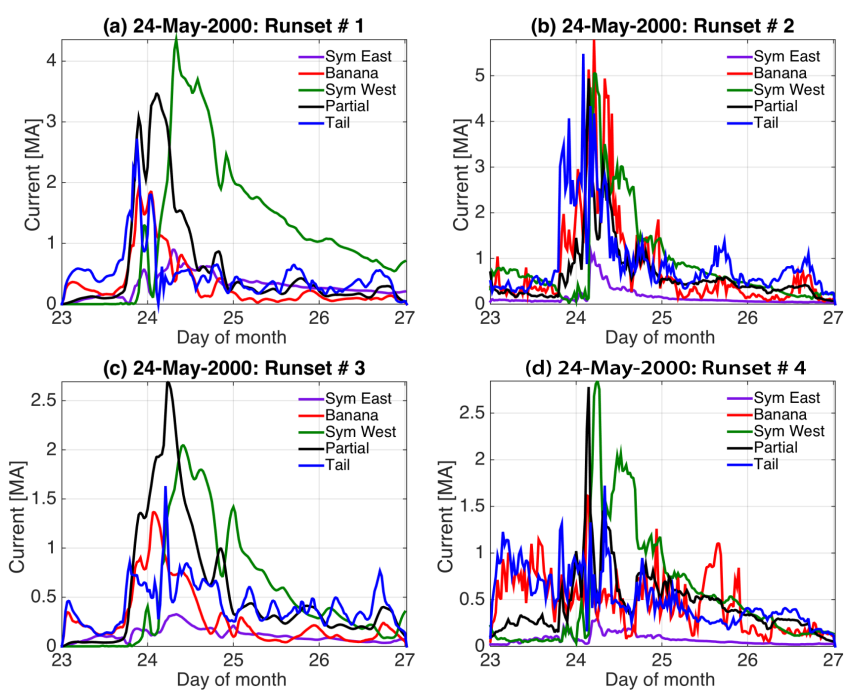

Figure 5. Normalized-timeline superposed epoch analysis of the DPS* time series from HEIDI for the four different runsets. The $x$ axis (epoch time) is binned every $30 \mathrm{~min}$ and the $y$ axis (DPS*) is divided into $5 \mathrm{nT}$ bins, with the color showing the number of values from all storms in each bin. The white curve displays the median and the purple curve shows the mean of the DPS* values. The four purple vertical lines are epoch time markers showing, from left to right, the start of the initial phase, the start of the main phase, the point in the main phase when the superposed average of Dst shows an inflection kink, and the storm peak.

The features of note in Fig. 5 are as follows. It is seen that the peak storm intensities for Runsets no. 1 and no. 2 (Fig. 5a and $\mathrm{b}$, the top row, both driven by the event-specific plasma data) are more negative than the peak median and mean values for Runsets no. 3 and no. 4 (Fig. 5c and d, the bottom row, both driven by the LANL reanalysis plasma data). It is also seen that the mean values (purple lines) are consistently more negative than the median values (white lines), as the few unusually large storms pull the mean down. This offset is $\sim 10 \mathrm{nT}$ at quiet times and up to $30 \mathrm{nT}$ at the storm peak.

The superposed epoch results for each current system will now be presented. Figure 6 shows the occurrence histograms (color), medians (white lines), and means (purple lines) for the partial ring current intensity along the normalized timeline for the four runsets. The color scale counting is in $30 \mathrm{~min}$ by $0.04 \mathrm{MA}$ bins. In all four plots, the median/mean peak value is reached just before $(\sim 1 \mathrm{~h})$ the Dst minimum and is between 1.5 and 2.3 MA. The partial ring current intensity then rapidly drops, falling to half of its peak value in $\sim 4 \mathrm{~h}$.

There are several features to note in Fig. 6. Runsets no. 1 and no. 3, which both use the Volland-Stern electric field, begin their increase at the start of the initial phase, while Runsets no. 2 and no. 4, which are driven by the self-consistent electric field, do not start increasing until the start of the main phase. In addition, the peak values in the VollandStern-driven simulations are smaller than those from the self- 

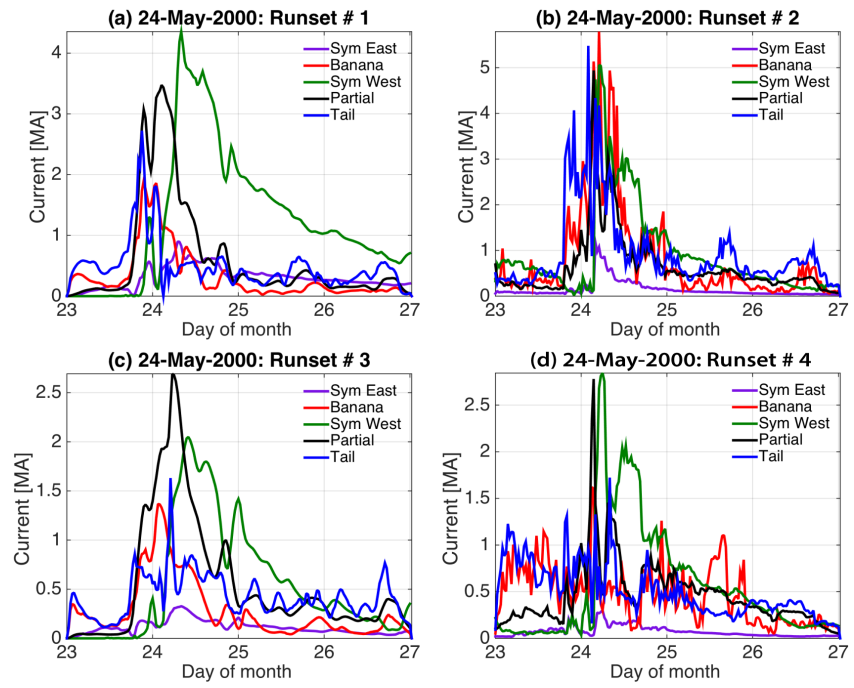

Figure 6. Normalized-timeline superposed epoch analysis of current within the HEIDI simulation domain classified as partial ring current, for the four runsets. The color shows the number of values in each $30 \mathrm{~min}$ by $0.05 \mathrm{MA}$ bin. The white curve is the median and the purple curve is the mean of the superposed currents and the four vertical purple lines are the epoch time markers used for normalization and/or reference.

consistent E-field simulations, and the peak values from the reanalysis boundary condition are smaller than those from the event-specific boundary fluxes. This produces a hierarchy of the peak values from Runset no. 4 as the lowest (mean peak partial ring current strength of 1.5 MA), Runsets no. 3 and no. 1 being incrementally higher (mean peak values of 1.8 and 2.1 MA, respectively), and Runset no. 2 being the largest (mean peak intensity of 2.3 MA).

The timing and intensity of the banana current is presented in Fig. 7. The format of the plots is the same as that in Fig. 6, with color showing the occurrence histogram and the white and black lines giving the median and mean, respectively. In general, these plots follow the same trends as with the partial ring current in Fig. 6; the banana current begins to rise early in the main phase, reaching a peak within a few hours before the storm peak, and then rapidly decreasing throughout the early recovery phase.

The key features to note from Fig. 7 are as follows. It is seen that in all of the panels, the banana current median and mean curves peak at or a little before the storm peak. In Runsets no. 1 and no. 2 , they reach a maximum $2-4 \mathrm{~h}$ before the storm peak, while in Runsets no. 3 and no. 4 , the max value occurs within an hour of the peak. There is the same shift in start time relative to the initial phase as seen in Fig. 6, with the runs with the Volland-Stern electric field starting to rise immediately and the self-consistent electric field simulations starting to rise a few hours later. The hierarchy of peak values is slightly different from the partial ring current results, with Runsets no. 3 the lowest (mean peak banana
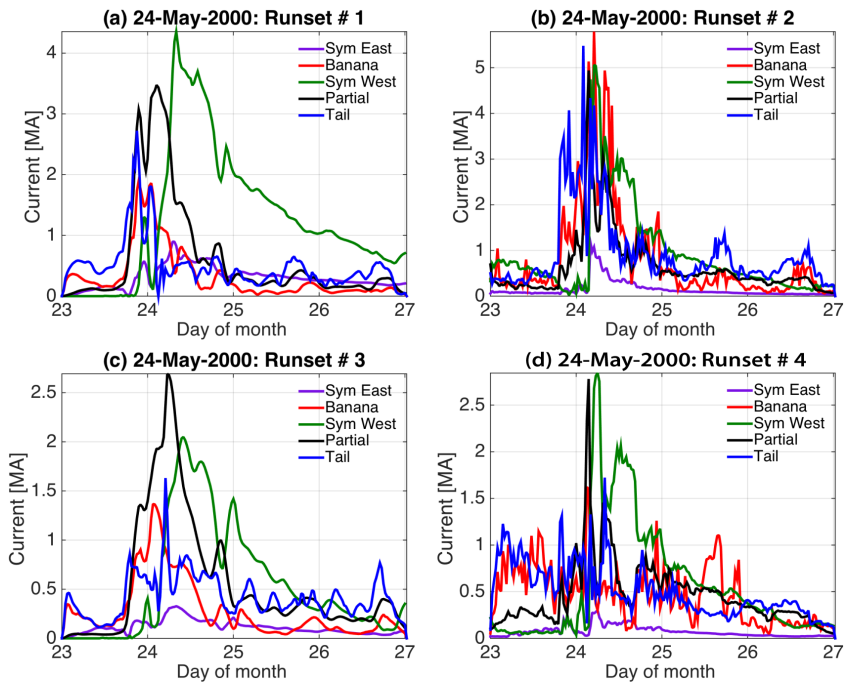

Figure 7. Normalized-timeline superposed epoch analysis of current in the HEIDI simulation domain classified as banana current, for the four runsets. The format is the same as Fig. 6 .

current strength of 1.1 MA), Runsets no. 1 and no. 4 just a bit higher (mean peak values of 1.2 and 1.3 MA, respectively), and finally Runset no. 2 with the largest banana current (mean maximum of 2.6 MA). Note that this peak value for the banana current in Runset no. 2 is slightly higher than the peak value of partial ring current from this runset.

Figure 8 shows the tail current results for the four HEIDI simulation sets. Remember that the applied definition for this tail current is the current intensity that crosses the outer boundary of the simulation domain, i.e., geosynchronous altitude. There is a similar trend as in the other plots with a rise at storm initiation, a peak just before the storm maximum, and then a rapid decrease during the early recovery phase. The timing has several important differences with those mentioned above however. Specifically, the maximum of the tail current is always before the storm peak, by $10 \mathrm{~h}$ in Runset no. 1 but only by $2 \mathrm{~h}$ in Runset no. 3 . The intensity hierarchy is the same as that for the banana current, with Runset no. 3 being the smallest (peak of 1.0 MA), then Runset no. 1 (1.4 MA), Runset no. 4 (1.6 MA), and again Runset no. 2 with the largest maximum mean value (2.7 MA).

The westward symmetric ring current statistics are shown in Fig. 9. The timing and intensity of this current system is completely different from all of the preceding ones. This current starts to rise halfway through the main phase, peaks within a few hours after the storm peak, and then slowly decreases throughout the rest of the recovery phase. The median curves (white lines) of all four runsets do not rise above the prestorm level until the epoch time is within $8 \mathrm{~h}$ of the storm peak. The mean curves (purple lines), however, start to rise a little earlier, as they are influenced by outlier simulation results more than the median curves. It is interesting to note that, for the Volland-Stern field simulations (Run- 

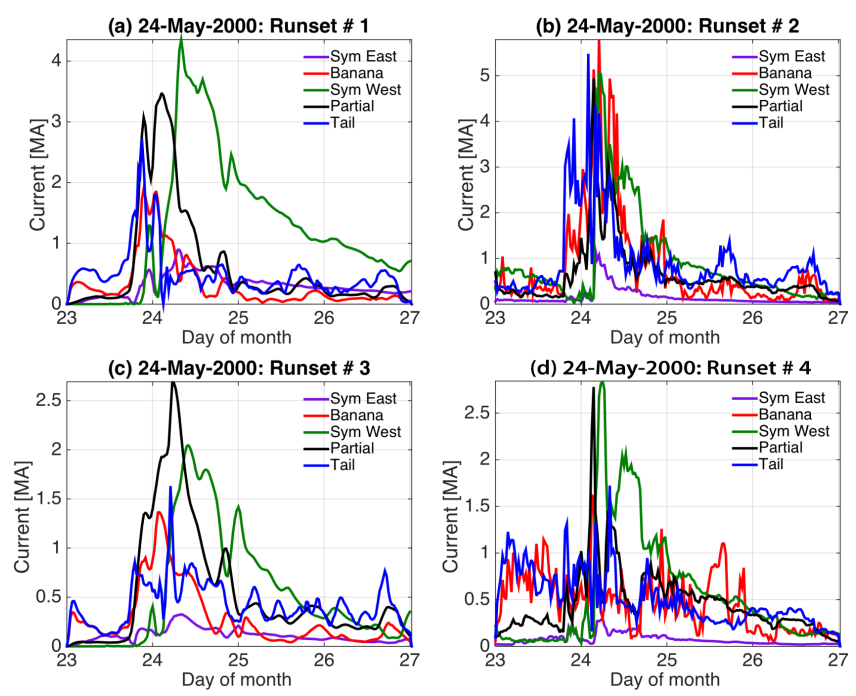

Figure 8. Normalized-timeline superposed epoch analysis of current designated as tail current inside of the HEIDI simulation domain for the four runsets. The format is the same as Fig. 6.

sets no. 1 and no. 3), the prestorm levels are small while the remnant westward symmetric ring current at the end of the epoch time are still rather large, especially for Runset no. 1 (median value of $0.7 \mathrm{MA}$ at an epoch time of $96 \mathrm{~h}$ ). For the self-consistent field simulations (Runsets no. 2 and no. 4), the prestorm and late recovery phase values are similar at 0.2-0.4 MA. The mean peak values have somewhat different ordering than the other current systems, with Runset no. 4 being the smallest (mean peak value of 1.2 MA), then Runset no. 3 (1.5 MA), then Runset no. 1 (1.9 MA), and finally Runset no. 2 with the largest mean peak westward symmetric ring current (2.0 MA).

The eastward ring current results are shown in Fig. 10. Note that the $y$ axis scale is half as large, so the 100 evenly spaced bins of current intensity are $0.02 \mathrm{MA}$ wide for the counting statistics. The timing of this current system is very similar to the westward symmetric ring current, with a rise from the prestorm value in the second half of the main phase, reaching a maximum value in the early recovery, and then a slow decay back to the prestorm current intensity. The magnitude of the eastward symmetric ring current, however, is substantially lower than the westward symmetric ring current. The mean peak values for all four runsets are between 0.1 and 0.4 MA, values that are not even twice the prestorm and late recovery values for this current system.

In order to more quantitatively compare the intensity and timing of the current systems relative to each other, Figs. 11 and 12 show the mean and median values of the current systems, respectively, for the four runsets of HEIDI. The five current systems are shown in different colors on the plots. The main difference between Figs. 11 and 12 is the intensity; the medians in Fig. 12 are all smaller than the means shown in Fig. 11, as expected for these positive-definite quantities
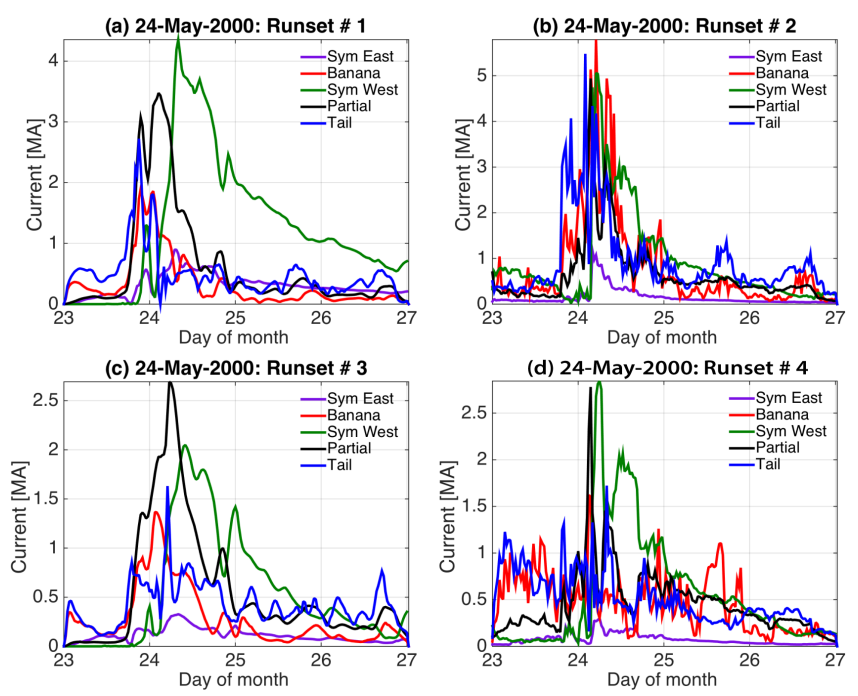

Figure 9. Normalized-timeline superposed epoch analysis of current designated westward symmetric ring current inside of HEIDI from the four runsets. The format is the same as Fig. 6 .
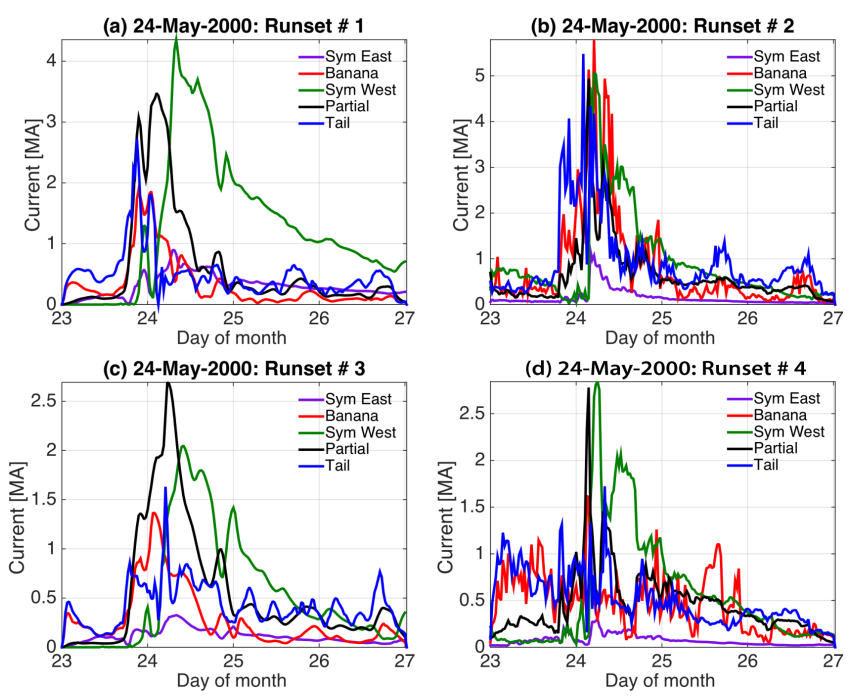

Figure 10. Normalized-timeline superposed epoch analysis of current designated eastward symmetric ring current inside of HEIDI from the four runsets. The format is the same as Fig. 6 .

with a skew towards the high-end positive values of the distribution.

In Figs. 11 and 12, it is seen that there is a similar pattern to the timing of the current systems in the HEIDI simulations, regardless of model setup configuration. The first current to rise during a storm sequence is the tail current, followed by the banana current, then the partial ring current, and finally the symmetric ring current. Another similarity between all of the runsets is that the duration of each current system's peak has a full width at half maximum of $>12 \mathrm{~h}$. That is, all of 

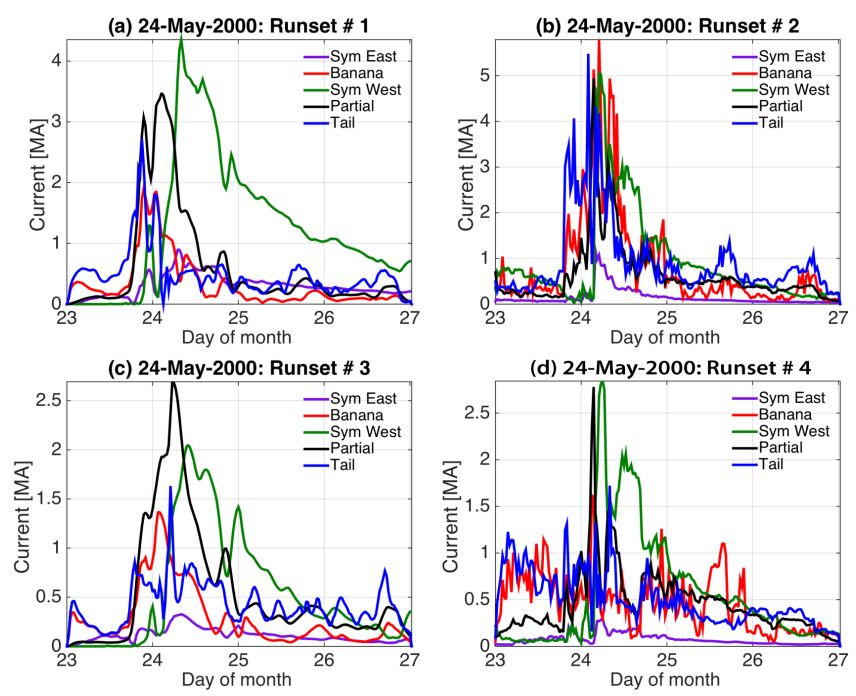

Figure 11. Normalized-timeline superposed epoch analysis showing the mean values of all current systems from HEIDI for the four runsets.

the currents are relatively long lasting in these intense storms included in this study.

There are distinct differences between the four runsets in Figs. 11 and 12 that are worth noting. For instance, it is seen that the Volland-Stern-driven results (Runsets no. 1 and no. 3) often produce larger partial and symmetric ring currents throughout the storm interval than are produced with the self-consistent electric field description (Runsets no. 2 and no. 4), by a factor of 10 to $40 \%$ depending on storm phase. Conversely, Runsets no. 2 and no. 4 have much larger tail and banana currents than are produced in Runsets no. 1 and no. 3, by at least $50 \%$ during both the main and recovery phases. In Runsets no. 1 and no. 3, the partial ring current is substantially bigger than either the tail current or banana current systems. This is not the case in Runsets no. 2 and no. 4, which have similarly sized peak intensities for the tail, banana, and partial ring currents.

\section{Discussion}

It has been shown above that the HEIDI model produces a systematic timing and intensity for the near-Earth current systems during intense storms. While the exact timing and intensity varies depending on the model configuration used for the simulation, the hierarchy is that the tail current peaks first, followed by the banana current, then partial ring current, and finally the symmetric (westward and eastward) ring currents.

\subsection{Relative timing of the current systems}

The ordering of the rise and fall of the various current systems can be explained as follows. As the convection electric
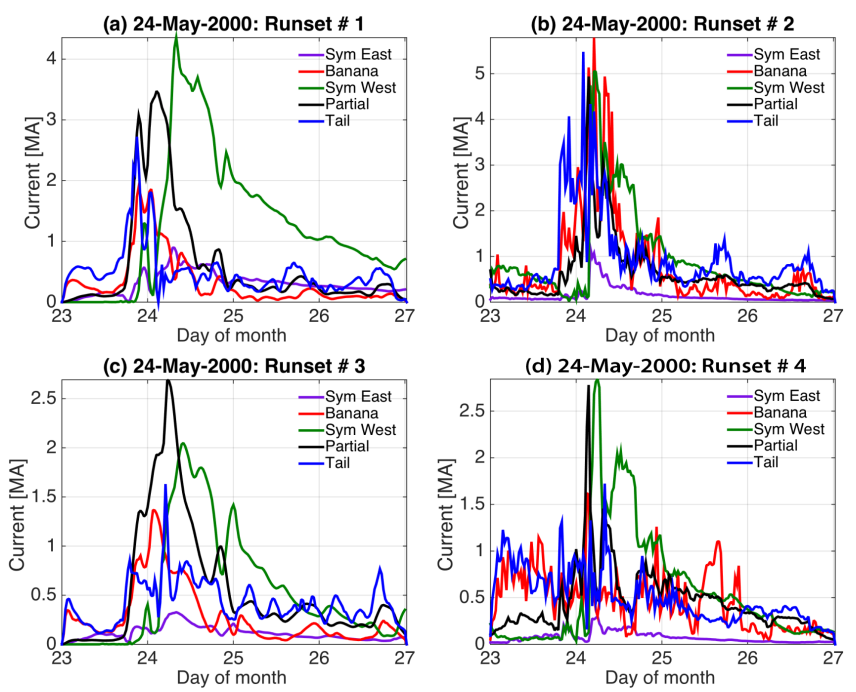

Figure 12. Normalized-timeline superposed epoch analysis showing the median values of all current systems from HEIDI for the four runsets.

field increases during the storm main phase, new plasma enters the simulation domain from the nightside plasma sheet. The plasma pressure peak initially straddles the outer boundary of the HEIDI domain. Therefore, the tail current, defined in this study as the current flowing radially through the outer simulation boundary, should be the first current system to show a rise in magnitude.

As the pressure peak fully enters the simulation domain, it is still out near geosynchronous orbit and the particles have not undergone very much adiabatic acceleration. So, the plasma pressure at the peak is only slightly larger than the pressure at the outer simulation boundary. Therefore, a strong partial ring current will not form just yet, but rather the banana current, with its loop around the plasma pressure peak, will be the next current system to ramp up during the storm development sequence.

The particles will continue to be convected inward, however, and the plasma pressure peak will increase in magnitude relative to the plasma pressure at the outer boundary. This causes the partial ring current to increase in intensity as the extra westward current around the outer slope of the pressure peak closes through field-aligned currents rather than through loops around the peak or out to the flank magnetopause. So, later in the main phase, the partial ring current will finally reach its maximum value. This situation will continue as long as the convective flow through the inner magnetosphere remains strong.

As convection wanes with the inevitable decrease in solar wind driving, the instantaneous drift paths of plasma still within the inner magnetosphere change from being "open" to being "closed". The term "instantaneous drift path" is defined here as the past and future trajectory of a selected particle calculated from the electric fields at a particular mo- 
ment in time. Trajectories that reach the magnetopause are classified as open and those that repeatedly circle the Earth are classified as closed. As the convection electric field decreases, this change of instantaneous drift paths from open to closed throughout much of phase space in the inner magnetosphere does not immediately change the current systems. After some time, however, the energy-dependent gradientcurvature drift dominating the particle motion in near-Earth space causes differential drift of what formerly were coherent plasma peaks. The localized pressure peaks will smooth out into a continuous ring of particles around the Earth. It is during this process that the partial ring current and banana current systems around each localized pressure peak will be converted into the symmetric ring current. The partial ring current will become the westward ring current and the banana current will split open and contribute equally to both the eastward and westward symmetric ring currents. This conversion takes place at some point during the early recovery phase.

\subsection{Relative intensity of the current systems}

As seen in Figs. 11 and 12, the westward symmetric ring current statistically dominates the current system intensities after just a few hours into the early recovery phase. It reaches its peak very soon after this, within the next $1-2 \mathrm{~h}$, and then starts to decline back to its prestorm value. This decline is slow and steady, being dominated by charge exchange loss (i.e., energetic $\mathrm{H}^{+}$and $\mathrm{O}^{+}$interacting with the neutral $\mathrm{H}$ geocorona), which is a function of species, radial distance, energy, and pitch angle. The gradual decay of the symmetric ring current is slower than the decay of the tail, banana, and partial ring current systems, all of which decayed very quickly after the drop in convective forcing. Every model setup, however, has some remnant level of each of these "main phase" current systems throughout the recovery of the storm. This is for two reasons. First, it takes a long time for the differential gradient-curvature drift to completely smooth out all of the localized pressure peaks. The lowerenergy particles take many hours just to make a single drift orbit around the Earth and so the smoothing of the localized peaks can take several days. Furthermore, small-intensity injections continue to occur during the recovery phase, leading to weak pressure peaks near the outer boundary of the simulation domain. These new peaks are localized and will have associated tail, banana, and partial ring current systems, each lasting several hours as the plasma drifts around to the dayside and either joins the symmetric ring current or leaves the system towards the dayside magnetopause.

It was shown that the eastward symmetric ring current is substantially smaller than all other near-Earth nightside current systems. A smaller eastward current is expected because of its location closer to Earth. In Eq. (1), therefore, the 1/ $B$ relationship yields a smaller $J_{\perp}$ on the inner side of the pressure peak. This is not only true for the same radial pres- sure gradient on each side of the peak, but also for a sharp inner pressure gradient. This is because the magnetic field decreases with radial distance as $r^{-3}$, which can overcome a steep inner pressure gradient. In addition, the steepest inner gradients occur during the main phase of storms after a fresh injection from the tail, when the pressure is asymmetric in local time. The eastward current around such localized peaks contribute to the banana current rather than the eastward symmetric ring current.

Another point of discussion is that the two different electric fields yield a distinctly different response. The VollandStern electric field produces a rather smooth pressure peak in the inner magnetosphere, with multiple pressure peaks only forming if subsequent injections from the plasma sheet flow through the simulation domain one after the other. Therefore, the banana current is usually just a single loop structure around the pressure peak, with occasionally a second banana current system forming around a subsequent injection peak.

The self-consistent electric field, however, sets up smallscale electric potential extrema throughout the inner magnetosphere, with a peak-valley pair associated with each pressure peak. The drift pattern associated with these local extrema create a twin vortex structure around the regions of upward and downward field-aligned current at the eastward and westward ends of the pressure peak region. These vortices, superimposed on the magnetospheric large-scale convection pattern, stagnate or even reverse the flow in the center of the pressure peak. A schematic of this relationship between the partial ring current, a localized pressure peak, and the local plasma flow direction is shown in Fig. 1b. Sometimes the feedback on the local plasma flows is strong enough to result in a split of the original peak into two smaller pressure peaks. These newly formed peaks will each have their own partial ring and banana current systems. This introduces a multiplication factor on partial ring and banana current system intensities, perhaps reaching a factor of 2 if the split in the pressure peak is so complete that it drops the plasma pressure to nearly zero where it used to have a maximum. It even results in an additional contribution to the tail current, if the pressure peak is close to this boundary (which is set at geosynchronous orbit for these simulations).

Therefore, the current systems have rather different intensities from the two electric field descriptions. The tail and banana current systems are much larger in the self-consistent electric field simulations (Runsets no. 2 and no. 4) than in the Volland-Stern field runs (Runsets no. 1 and no. 3). The partial ring current is on average biggest in Runset no. 2, but this is followed closely by Runset no. 1 . Runset no. 1 has such a large partial ring current because these are intense storms and the smooth electric field creates a large plasma pressure peak deep within the inner magnetosphere. This results in a rather large partial ring current and subsequent westward symmetric ring current.

Another difference between the results from the two electric field descriptions is the magnitude of the asymmetric 
current systems in the late recovery phase. Many hours past the storm peak, the tail, banana, and partial ring currents are roughly twice as large in the self-consistent runs as they are in the Volland-Stern simulations. Note that they are still relatively small with most of the means and medians for these currents in the late recovery phase being only a few tenths of a mega ampere. Any injection, however, even in the late recovery, produces a pressure crescent that is subject to the negative feedback effects of the self-consistent electric field. The breakup of the original pressure peak into multiple peaks yields an asymmetric current system around each of these new pressure peaks, thereby increasing the magnitude of these currents.

There is also a systematic difference based on the plasma outer boundary condition applied. Runsets no. 1 and no. 2 used the event-specific LANL observations while Runsets no. 3 and no. 4 used the O'Brien and Lemon (2007) moments based on a reanalysis of the LANL observations. For reference, Fig. 3 of Katus et al. (2015) shows the superposed epoch time series, on the same normalized timeline as used here, of the density and temperature moments for the two outer boundary conditions. The event-specific values should be more correct for any particular storm but might have significant temporal gaps when there are no LANL satellites on the nightside. The reanalysis boundary condition is more complete in that it provides a full local time distribution across the nightside by filling in any gaps with values from times with similar solar and geophysical conditions. The resolution of the reanalysis values is a $1 \mathrm{~h}$ time step, however, which smooths out any transient spikes in the inflowing plasma sheet and could be inserting erroneous plasma values in the gap regions. Neither is perfectly ideal and therefore both boundary conditions were applied for this study.

It is seen that Runsets no. 1 and no. 2 (event-specific) yield larger-intensity current systems than those produced in Runsets no. 3 and no. 4 (reanalysis). The ordering of the peaks in the means and medians in Figs. 11 and 12 are similar between the two outer boundary conditions, except that the magnitudes are systematically smaller with the reanalysis values applied. Another slight difference is that the tail current remains elevated a bit longer through the main phase with the reanalysis boundary condition. In Runsets no. 3 and no. 4, the tail current is still the first current system to ramp up at the initiation of a storm, but it remains elevated and reaches its peak later in the main phase than in Runsets no. 1 and no. 2 .

\subsection{Analysis of the total current}

It should be noted which current system contributes to the westward or eastward azimuthal current in near-Earth space. The symmetric ring currents are easily classified, as their names imply. The tail and partial ring current are westwardonly current systems, but the banana current flows both westward and eastward. Because this current system loops around a plasma pressure peak, it contributes equally to the total current flowing in the eastward and westward directions. Another point to make about the directionality of the current systems is that their values at a particular time cannot be simply added to yield the total westward or eastward current flowing in the inner magnetosphere. The asymmetric currents can be either localized or very broad in local time extent and do not necessarily overlap in local time. Similarly, there can be multiple peaks in the symmetric pressure distribution resulting in several rings of symmetric westward and eastward current. Therefore, the current system time series shown in the Results section above should be considered as "the sum of all current loops of this type within the simulation domain". It could be a single loop of current but it does not have to be and probably is not for the self-consistent electric field simulations.

Regarding data-model comparisons and the validity of these results, they are in line with case study and statistical analyses of currents in near-Earth space. To get the total current, however, the time series of the current system averages cannot be simply summed to get a total westward or eastward current because multiple, non-overlapping current loops could be contributing to each of the asymmetric current systems. The total westward current peaks at a value between 2 and 10 MA during the main phase of the storm and drops below 1 MA within a day after storm peak, and usually much faster than this. Values like this are in general agreement with the total current values from the statistical studies of Jorgensen et al. (2004) and Le et al. (2004).

A similar statement can be made regarding current densities. Lui and Hamilton (1992) calculated current densities from ions of $>25 \mathrm{keV}$ during quiet times, finding that the peak was $2-4 \mathrm{nA} \mathrm{m}^{-2}$, in agreement with the pre-storm and late recovery phase current densities shown above. The storm-time current densities are higher than those from Lui et al. (1987), who found that current densities peaked at 5$8 \mathrm{nA} \mathrm{m}^{-2}$ during two magnetic storms, but again this is for ions above $25 \mathrm{keV}$, which misses a substantial portion of the storm-time energy content. The empirical modeling of Tsyganenko (2000) and Le et al. (2004), fitting binned magnetometer data with current densities, shows azimuthal current density of a few $\mathrm{nA} \mathrm{m}^{-2}$ for nominal quiet time conditions, also in agreement with the quiet time values shown above. The Le et al. (2004) results reveal that average nightside current densities exceed $10 \mathrm{nA} \mathrm{m}^{-2}$ for moderate storm conditions of Dst between -80 and $-100 \mathrm{nT}$. This is in line with the current densities shown above.

It should be noted that there is some disagreement among observational studies surrounding the current density and total current in the inner magnetosphere. Data from the AMPTE-CCE, CRRES, and Polar satellites were used to obtain statistical representations of the locations and intensities of the westward and eastward current systems in near-Earth space (e.g., Lui et al., 1987; Spence et al., 1989; Iijima et al., 1990; Lui and Hamilton, 1992; Jorgensen et al., 2004; Le et 
al., 2004). Jorgensen et al. (2004), for example, found quiet time current densities of a few $\mathrm{nA} \mathrm{m}^{-2}$ and storm time values that reached and sometimes exceeded $10 \mathrm{nA} \mathrm{m}^{-2}$. These values lead to total westward currents below 10 MA, even for intense storms reaching Dst of $-150 \mathrm{nT}$. In contrast, Vallat et al. (2005) used the curlometer technique on data from the near-Earth tetrahedral Cluster campaigns to calculate current vectors in the inner magnetosphere, finding $10-20 \mathrm{nA} \mathrm{m}^{-2}$ westward currents in nearly every usable near-Earth pass, with extreme values above $50 \mathrm{nA} \mathrm{m}^{-2}$. Zhang et al. (2011) and Shen et al. (2014) confirmed this analysis of Cluster curlometer inner magnetospheric current densities for all local times, finding a persistent westward current density of 9-27 nA m ${ }^{-2}$ for non-storm times (Zhang et al., 2011) and up to $37 \mathrm{nA} \mathrm{m}^{-2}$ during superstorm conditions (Shen et al., 2014). Grimald et al. (2012) tested the validity of the Cluster curlometer technique with a known magnetic field configuration, determining that the errors were too great inside of $3 R_{\mathrm{E}}$ but that the observational distances in the Vallat et al. (2005) study (perigee of $4 R_{\mathrm{E}}$ ) were acceptable. Regarding other modeling studies, empirical magnetic field models show that near-Earth current can exceed 10 MA (e.g., Tsyganenko et al., 2003; Tsyganenko and Sitnov, 2005), but the spatially averaged nature of such models never yields current densities in the range seen by the curlometer. First-principles numerical modeling shows that such large current densities exist in the results (e.g., Liemohn et al., 2001b; Ganushkina et al., 2012b) but only during intense storm main phases, not during quiet intervals.

It is useful to compare these results with the timing and intensity from the Asikainen et al. (2010) Dst prediction algorithm. They found that the tail current ramps up quickly during the main phase and peaks well before the storm minimum is reached. That study did not separate the symmetric, partial, or banana currents from each other, designating them all as "ring current" in that analysis. It could also be that the "tail current" contribution in that model includes perturbations from some of the other asymmetric current systems. Regardless, what they designate as tail current occasionally dominates the Dst perturbation very early in the main phase, but usually is less than half of the current designated as "ring current" in the model. This is very similar to the findings here, with the tail current in the present study dominating the current systems early in the main phase, then yielding to, at most, a third of the total asymmetric current during the late main phase, and dropping off rapidly during the early recovery phase.

\subsection{Caveats}

There are several important caveats to the results and discussion above. The first is that a dipolar magnetic field was assumed for all of these calculations. This is a useful approximation for the inner magnetosphere, as the typical distortion in this region does not invalidate the usage of such a magnetic field description. It is not correct, however, and the deviations of the magnetic field from a dipolar configuration will certainly change the drift paths and current calculations expected from the model. For instance, several studies have found that the plasma pressure peak is significantly reduced in the presence of a non-dipolar magnetic field (e.g., Chen et al., 2006; Zaharia et al., 2006; Ilie et al., 2012). The two field descriptions, however, produce similar groundbased magnetic perturbations because the current resulting from that lowered plasma pressure is larger, as given by the $1 / B$ dependence in Eq. (1). Ganushkina et al. (2012a) conducted an extensive study on the influence of magnetic field choice and perturbation calculation scheme for evaluating inner magnetospheric drift physics modeling results, concluding that a non-dipolar field with a full Biot-Savart integral of the ground-based perturbation yields a larger simulated Dst than the DPS relation applied to a dipolar field particle calculation. These studies exemplify the need for a fully selfconsistent calculation, not only with respect to the electric field, but also with regard to the magnetic field.

A second point to note about the results is that the magnitude of a particular current system does not translate into an equivalent contribution to the in situ or ground-based magnetic field distortion. While both the partial ring current and tail current are westward-flowing systems, their contributions to Dst or SYM-H are not equal for a given current system intensity. That is, the tail current is systematically located farther away from Earth than is the partial ring current. While they can sometimes be located at different latitudes on the same magnetic field line, especially early in the main phase (see Liemohn et al., 2011b), the $1 / r^{2}$ dependence in the Biot-Savart law means that the tail current usually has a smaller contribution to ground-based perturbations than does a similarly sized partial ring current (see Liemohn, 2003). Moreover, the banana current has very little contribution to the ground-based perturbation, as found by Liemohn et al. (2013a). Because the banana current is a loop surrounding a plasma pressure peak, it has a large contribution to magnetic field distortion inside the loop (associated with the diamagnetic cavity of the plasma pressure peak) but its contribution to $\Delta B$ falls off quickly with distance outside of the loop.

A third caveat is that the tail current is underestimated in all of these calculations. The definition of tail current used in this study is that current which passes through the outer boundary of the simulation domain. Such current could belong to any system. Indeed, Liemohn et al. (2011b, 2013b) showed that the symmetric ring current can extend out to $10 R_{\mathrm{E}}$ downtail during the late main phase and early recovery phase. A comparison should be made with other modeling approaches, such as the event-oriented magnetic field model, which has been also used to successfully study the evolution of the ring current, the tail current, and the magnetopause currents during geomagnetic storms and estimate their relative contributions to the Dst (actually SYM-H was 
used) index (Ganushkina et al., 2004, 2010; Kalegaev et al., 2005). It was found that during a storm, the tail current intensifies first and tracks the drop in the Dst index (SYM-H). Ganushkina et al. (2004) found a Dst transition of roughly $-150 \mathrm{nT}$, where storms smaller than this level have a Dst (SYM-H) index dominated by the tail current and more intense magnetic storms have Dst (SYM-H) dominated by the ring current. Dubyagin et al. (2014) have further quantified the contribution to the SYM-H and ASY-H magnetic activity indices from various current systems across a large number of storms for several empirical magnetic field models. The study presented above does not go the extra step of calculating the relative contribution of these current systems to the simulated or observed ground-based magnetic perturbation.

\section{Conclusions}

This study addressed the question of the intensity and timing of various near-Earth current systems during magnetic storms. Specifically, it presented results for the tail current, banana current, partial ring current, and westward and eastward symmetric ring currents as extracted from simulation results. The study considered 90 intense magnetic storm intervals and four configurations for the HEIDI model, applying specified definitions for each current system to obtain time series values for each of the 360 simulations. Results from the 24 May 2000 magnetic storm were shown as an example case study to establish the relationship between the plasma pressure, the spatial distribution of the currents, and the time evolution of the magnitude of the current systems. The results from all of the storms were then superposed along a normalized epoch timeline, expanding or contracting the length of each phase of every storm to the average length of that storm phase. Occurrence frequency distributions as well as means and medians of the superposed currents were analyzed.

It was found that there is a systematic ordering to the current systems, with the tail current rising first at the initiation of activity, followed by the banana current and then partial ring current during the main phase. These "asymmetric" current systems rapidly decreased in intensity after the storm peak. The two symmetric current systems started to rise only late in the main phase, peaked early in the recovery phase, and then steadily declined in intensity throughout the rest of the recovery phase. This ordering (tail, banana, partial ring, symmetric ring) was seen in all four simulation configurations.

The peak intensities of the current systems depended on the simulation configuration, with the mean values $\sim 20 \%$ larger than the median values for most of the epoch time interval. Quoting the peak amplitudes from the mean time series of Runset no. 2 (Fig. 11b), the tail current reached 2.7 MA, the banana current rose to $2.6 \mathrm{MA}$, the partial ring current topped out at $2.3 \mathrm{MA}$, the westward symmetric ring current climbed to $2.1 \mathrm{MA}$, and the eastward symmetric ring current barely made it up $0.25 \mathrm{MA}$. All of these peak mean values occur within $10 \mathrm{~h}$ of each other, from the early main phase to the early recovery phase. Furthermore, the full width at half maximum width of each current system time series is at least $12 \mathrm{~h}$.

The intensity of the current systems varies dramatically with the electric field setup. The Volland-Stern electric field yields smooth pressure peaks while the self-consistent electric field produces small-scale structure embedded within the larger pressure crescent in the inner magnetosphere. This difference makes the tail and banana currents significantly larger in the runs with the self-consistent electric field compared to those with the Volland-Stern electric field. The partial ring current was roughly the same regardless of electric field choice; the Volland-Stern runs have a large pressure peak close to the Earth, which yields an intense partial ring current, while the self-consistent electric field has several smaller partial ring current loops adding to a similarly sized total value. Another difference between the results from these electric field descriptions is that the self-consistent electric field produces about twice as much asymmetric current (tail, banana, and partial ring) in the late recovery phase than the Volland-Stern field.

The outer plasma boundary condition had a much smaller influence on the current intensities and timings. The eventspecific boundary condition produced current systems that were slightly stronger than those from the reanalyzed boundary condition. The reanalyzed boundary condition also yielded a delayed peak to the tail current system magnitude, cresting later in the main phase than the tail current peak produced from the event-specific boundary condition.

Finally, it should be remembered that the current system intensities are the sum of all current loops of this type within the HEIDI simulation domain at that time. It could be a single loop of current, but it does not have to be and, depending on the current system, run configuration, and storm phase, probably is not a single loop.

Acknowledgements. The authors thank the sponsors of this research, in particular research grants from NASA (NNX08AQ15G, NNX09AF45G, NNX10AQ34C, NNX11AO60G, and NNX14AC02G) and NSF (ATM-0802705, ATM-0903596, and AGS-1102863). This includes a NASA GSRP fellowship for Dr. Katus. The authors thank the International Space Science Institute (ISSI) in Bern, Switzerland for its support of an international team on "Resolving Current Systems in Geospace". Solar wind data was obtained from CDAWeb at NASA GSFC in Greenbelt, Maryland, USA, Dst values are from WDC-2 in Kyoto, Japan, and event-specific geosynchronous data are from Los Alamos National Laboratory. Plots of the model results are available at the Virtual Model Repository (http://vmr.engin.umich.edu/) and the full output from the simulation runsets (several tens of GB) are available upon request to the authors. The graphics in Fig. 1 were produced by Sande Wetmore of the University of Michigan. 
The topical editor G. Balasis thanks I. Dandouras and one anonymous referee for help in evaluating this paper.

\section{References}

Antonova, E. E. and Ganushkina, N. Y.: Inner magnetospheric currents and their role in the magnetosphere dynamics, Phys. Chem. Earth (C), 25, 23-26, 2000.

Antonova, E. E., Kirpichev, I. P., Vovchenko, V. V., Stepanova, M. V., Riazantseva, M. O., Pulinets, M. S., Ovchinnikov, I. L., and Znatkova, S. S.: Characteristics of plasma ring, surrounding the Earth at geocentric distances $\sim 7-10 \mathrm{RE}$ and magnetospheric current systems, J. Atmos. Solar-Terr. Phys., 99, 85-91, 2013.

Asikainen, T., Maliniemi, V., and Mursula, K.: Modeling the contributions of ring, tail, and magnetopause currents to the corrected Dst index, J. Geophys. Res., 115, A12203, doi:10.1029/2010JA015774, 2010.

Bame, S. J., McComas, D. J., Thomsen, M. F., Barraclough, B. L., Elphic, R. C., Glore, J. P., Gosling, J. T., Chavez, J. C., Evans, E. P., and Wymer, F. J.: Magnetospheric plasma analyzer for spacecraft with constrained resources, Rev. Sci. Instrum., 64, 1026, doi:10.1063/1.1144173, 1993.

Belian, R. D., Gisler, G. R., Cayton, T., and Christensen, R.: High-Z energetic particles at geosynchronous orbit during the great solar proton event series of October 1989, J. Geophys. Res., 97, 16897, doi:10.1029/92JA01139, 1992.

Birmingham, T. J.: Birkeland currents in an anisotropic, magnetostatic plasma, J. Geophys. Res., 97, 3907, doi:10.1029/91JA03029, 1992.

Brandt, P. C:son, Mitchell, D. G., Ebihara, Y., Sandel, B. R., Roelof, E. C., Burch, J. L., and Demajistre, R.: Global IMAGE/HENA observations of the ring current: Examples of rapid response to IMF and ring current-plasmasphere interaction, J. Geophys. Res., 107, 1359, doi:10.1029/2001JA000084, 2002.

Burton, R. K., McPherron, R. L., and Russell, C. T.: An empirical relationship between interplanetary conditions and Dst, J. Geophys. Res., 80, 4204-4214, 1975.

Buzulukova, N., Fok, M.-C., Goldstein, J., Valek, P., McComas, D. J., and Brandt, P. C.: Ring current dynamics in moderate and strong storms: Comparative analysis of TWINS and IMAGE/HENA data with the Comprehensive Ring Current Model, J. Geophys. Res., 115, A12234, doi:10.1029/2010JA015292, 2010.

Chen, M. W., Liu, S., Schulz, M., Roeder, J. L., and Lyons, L. R.: Magnetically self-consistent ring current simulations during the 19 October 1998 storm, J. Geophys. Res., 111, A11S15, doi:10.1029/2006JA011620, 2006.

Chiu, Y. T. and Schulz, M.: Self-consistent particle and parallel electrostatic field distributions in the magnetosphericionospheric auroral region, J. Geophys. Res., 83, 629, doi:10.1029/JA083iA02p00629, 1978.

Dessler, A. J. and Parker, E. N.: Hydromagnetic Theory of Geomagnetic Storms, J. Geophys. Res., 64, 2239-2252, doi:10.1029/JZ064i012p02239, 1959.

Dubyagin, S., Ganushkina, N., Apatenkov, S., Kubyshkina, M., Singer, H., and Liemohn, M.: Geometry of duskside equatorial current during magnetic storm main phase as deduced from mag- netospheric and low-altitude observations, Ann. Geophys., 31, 395-408, doi:10.5194/angeo-31-395-2013, 2013 a.

Dubyagin, S., Ganushkina, N., Apatenkov, S., Kubyshkina, M., Ohtani, S.-I., Singer, H., and Liemohn, M.: Storm-time duskside equatorial current and its closure path, J. Geophys. Res. Space Physics, 118, 5616-5625, doi:10.1002/jgra.50512, 2013b.

Dubyagin, S., Ganushkina, N. Y., Kubyshkina, M., and Liemohn, M. W.: Contribution from different current systems to SYM and ASY mid-latitude indices, J. Geophys. Res. Space Physics, 119, 7243-7263, doi:10.1002/2014JA020122, 2014.

Fok, M.-C., Kozyra, J. U., Nagy, A. F., Rasmussen, C. E., and Khazanov, G. V.: A decay model of equatorial ring current and the associated aeronomical consequences, J. Geophys. Res., 98, 19381, doi:10.1029/93JA01848, 1993.

Ganushkina, N. Y., Pulkkinen, T. I., Kubyshkina, M. V., Singer, H. J., and Russell, C. T.: Modeling the ring current magnetic field during storms, J. Geophys. Res., 107, SMP 3-1-SMP 3-13, doi:10.1029/2001JA900101, 2002.

Ganushkina, N. Yu., Pulkkinen, T. I., Kubyshkina, M. V., Singer, H. J., and Russell, C. T.: Long-term evolution of magnetospheric current systems during storms, Ann. Geophys., 22, 1317-1334, doi:10.5194/angeo-22-1317-2004, 2004.

Ganushkina, N. Yu., Liemohn, M. W., Kubyshkina, M. V., Ilie, R., and Singer, H. J.: Distortions of the magnetic field by storm-time current systems in Earth's magnetosphere, Ann. Geophys., 28, 123-140, doi:10.5194/angeo-28-123-2010, 2010.

Ganushkina, N. Yu., Liemohn, M. W., and Pulkkinen, T. I.: Stormtime ring current: model-dependent results, Ann. Geophys., 30, 177-202, doi:10.5194/angeo-30-177-2012, 2012a.

Ganushkina, N. Y., Dubyagin, S., Kubyshkina, M., Liemohn, M. W., and Runov, A.: Inner magnetosphere currents during the CIR/HSS storm on 21-23 July 2009, J. Geophys. Res., 117, A00L04, doi:10.1029/2011JA017393, 2012b.

Grimald, S., Dandouras, I., Robert, P., and Lucek, E.: Study of the applicability of the curlometer technique with the four Cluster spacecraft in regions close to Earth, Ann. Geophys., 30, 597611, doi:10.5194/angeo-30-597-2012, 2012.

Iijima, T., Potemra, T. A., and Zaneti, L. J.: Large-scale characteristics of magnetospheric equatorial currents, J. Geophys. Res., 95, 991-999, 1990.

Ilie, R., Liemohn, M. W., Thomsen, M. F., Borovsky, J. E., and Zhang, J.: The influence of epoch time selection when doing superposed epoch analysis on ACE and MPA data, J. Geophys. Res., 113, A00A14, doi:10.1029/2008JA013241, 2008.

Ilie, R., Liemohn, M. W., Toth, G., and Skoug, R.: Kinetic model of the inner magnetosphere with arbitrary magnetic field, J. Geophys. Res., 117, A04208, doi:10.1029/2011JA017189, 2012.

Jordanova, V. K., Kozyra, J. U., Khazanov, G. V., Nagy, A. F., Rasmussen, C. E., and Fok, M.-C.: A bounce-averaged kinetic model of the ring current ion population, Geophys. Res. Lett., 21, 2785, doi:10.1029/94GL02695, 1994.

Jorgensen, A. M., Spence, H. E., Hughes, W. J., and Singer, H. J.: A statistical study of the global structure of the ring current, J. Geophys. Res., 109, A12204, doi:10.1029/2003JA010090, 2004.

Kalegaev, V. V., Ganushkina, N. Y., Pulkkinen, T. I., Kubyshkina, M. V., Singer, H. J., and Russell, C. T.: Relation between the ring current and the tail current during magnetic storms, Ann. Geophys., 23, 523-533, doi:10.5194/angeo-23-523-2005, 2005. 
Katus, R., Liemohn, M. W., Gallagher, D. L., Ridley, A., and Zou, S.: Evidence for potential and inductive convection during intense geomagnetic events using normalized superposed epoch analysis, J. Geophys. Res. Space Physics, 118, 181-191, doi:10.1029/2012JA017915, 2013.

Katus, R. M., Liemohn, M. W., Ionides, E., Ilie, R., Welling, D. T., and Sarno-Smith, L. K.: Statistical analysis of the geomagnetic response to different solar wind drivers and the dependence on storm intensity, J. Geophys. Res. Space Physics, 120, 310-327, doi:10.1002/2014JA020712, 2015.

Kubyshkina, M., Pulkkinen, T. I., Ganushkina, N. Y., and Partamies, N.: Magnetospheric currents during sawtooth events: Event-oriented magnetic field model analysis, J. Geophys. Res., 113, A08211, doi:10.1029/2007JA012983, 2008.

Le, G., Russell, C. T., and Takahashi, K.: Morphology of the ring current derived from magnetic field observations, Ann. Geophys., 22, 1267-1295, doi:10.5194/angeo-22-1267-2004, 2004.

Lemaire, J. and Sherer, M.: Simple model for an ionexosphere in an open magnetic field, Phys. Fluids, 14, 1683, doi:10.1063/1.1693664, 1971.

Liemohn, M. W.: Yet another caveat to the DesslerParker-Sckopke relation, J. Geophys. Res., 108, 1251, doi:10.1029/2003JA009839, 2003.

Liemohn, M. W. and Brandt, P. C.: Small-scale structure in the stormtime ring current, Inner Magnetosphere Interactions: New Perspectives from Imaging, AGU Monogr. Ser., vol. 159, edited by: Burch, J. L., Schulz, M., and Spence, H., p. 167, Am. Geophys. Un., Washington, DC, 2005.

Liemohn, M. W. and Jazowski, M.: Ring current simulations of the 90 intense storms during solar cycle 23, J. Geophys. Res., 113, A00A17, doi:10.1029/2008JA013466, 2008.

Liemohn, M. W. and Katus, R.: Is the storm time response of the inner magnetospheric hot ions universally similar or driver dependent?, J. Geophys. Res., 117, A00L03, doi:10.1029/2011JA017389, 2012.

Liemohn, M. W. and Khazanov, G. V.: Collisionless plasma modeling in an arbitrary potential energy distribution, Phys. Plasmas, 5, 580, doi:10.1063/1.872750, 1998.

Liemohn, M. W., Kozyra, J. U., Jordanova, V. K., Khazanov, G. V., Thomsen, M. F., and Cayton, T. E.: Analysis of early phase ring current recovery mechanisms during geomagnetic storms, Geophys. Res. Lett., 25, 2845, doi:10.1029/1999GL900611, 1999.

Liemohn, M. W., Kozyra, J. U., Thomsen, M. F., Roeder, J. L., Lu, G., Borovsky, J. E., and Cayton, T. E.: Dominant role of the asymmetric ring current in producing the stormtime Dst*, J. Geophys. Res., 106, 10883, doi:10.1029/2000JA000326, 2001 a.

Liemohn, M. W., Kozyra, J. U., Clauer, C. R., and Ridley, A. J.: Computational analysis of the near-Earth magnetospheric current system, J. Geophys. Res., 106, 29531, doi:10.1029/2001JA000045, 2001b

Liemohn, M. W., Ridley, A. J., Gallagher, D. L., Ober, D. M., and Kozyra, J. U.: Dependence of plasmaspheric morphology on the electric field description during the recovery phase of the April 17, 2002 magnetic storm, J. Geophys. Res., 109, A03209, doi:10.1029/2003JA010304, 2004.

Liemohn, M. W., Ridley, A. J., Brandt, P. C., Gallagher, D. L., Kozyra, J. U., Mitchell, D. G., Roelof, E. C., and DeMajistre, R.: Parametric analysis of nightside conductance effects on inner magnetospheric dynamics for the 17 April 2002 storm, J. Geophys. Res., 110, A12S22, doi:10.1029/2005JA011109, 2005.

Liemohn, M. W., Ridley, A. J., Kozyra, J. U., Gallagher, D. L., Thomsen, M. F., Henderson, M. G., Denton, M. H., Brandt, P. C., and Goldstein, J.: Analyzing electric field morphology through data-model comparisons of the GEM IM/S Assessment Challenge events, J. Geophys. Res., 111, A11S11, doi:10.1029/2006JA011700, 2006.

Liemohn, M. W., Jazowski, M., Kozyra, J. U., Ganushkina, N., Thomsen, M. F., and Borovsky, J. E.: CIR vs. CME drivers of the ring current during intense magnetic storms, Proc. Roy. Soc. A, 466, 3305-3328, doi:10.1098/rspa.2010.0075, 2010.

Liemohn, M. W., Ilie, R., Ganushkina, N., Kozyra, J. U., Ridley, A. J., Thomsen, M. F., and Borovsky, J. E.: Testing the necessity of transient spikes in the storm-time ring current drivers, J. Geophys. Res., 116, A04226, doi:10.1029/2010JA015914, 2011a.

Liemohn, M. W., De Zeeuw, D. L., Ilie, R., and Ganushkina, N. Y.: Deciphering magnetospheric cross-field currents, Geophys. Res. Lett., 38, L20106, doi:10.1029/2011GL049611, 2011b.

Liemohn, M. W., Ganushkina, N. Y., Katus, R. M., De Zeeuw, D. L., and Welling, D. T.: The magnetospheric banana current, J. Geophys. Res., 118, 1009-1021, doi:10.1002/jgra.50153, 2013a.

Liemohn, M. W., De Zeeuw, D. L., Ganushkina, N. Y., Kozyra, J. U., and Welling, D. T.: Magnetospheric crossfield currents during the January 6-7, 2011, high-speed stream-driven interval, J. Atmos. Solar-Terr. Phys., 99, 78-84, doi:10.1016/j.jastp.2012.09.007, 2013b.

Lui, A. T. Y. and Hamilton, D. C.: Radial profiles of quiet time magnetospheric parameters, J. Geophys. Res., 97, 19325-19332, 1992.

Lui, A. T. Y., McEntire, R. W., and Krimigis, S. M.: Evolution of the ring current during two geomagnetic storms, J. Geophys. Res., 92, 7459-7470, doi:10.1029/JA092iA07p07459, 1987.

Mauk, B. H. and Zanetti, L. J.: Magnetospheric electric fields and currents, Rev. Geophys., 25, 541, doi:10.1029/RG025i003p00541, 1987.

Maynard, N. C. and Chen, A. J.: Isolated cold plasma regions: Observations and their relation to possible production mechanisms, J. Geophys. Res., 80, 1009, doi:10.1029/JA080i007p01009, 1975.

O'Brien, T. P. and Lemon, C. L.: Reanalysis of plasma measurements at geosynchronous orbit, Space Weather, 5, S03007, doi:10.1029/2006SW000279, 2007.

Parker, E. N.: Newtonian development of the dynamical properties of ionized gases of low density, Phys. Rev., 107, 924, doi:10.1103/PhysRev.107.924, 1957.

Ridley, A. J. and Liemohn, M. W.: A model-derived description of the penetration electric field, J. Geophys. Res., 107, 1151, doi:10.1029/2001JA000051, 2002.

Ridley, A. J., De Zeeuw, D. L., Gombosi,T. I., and Powell, K. G.: Using steady-state MHD results to predict the global state of the magnetosphere-ionosphere system, J. Geophys. Res., 106, 30067, doi:10.1029/2000JA002233, 2001.

Ridley, A. J., Gombosi, T. I., and DeZeeuw, D. L.: Ionospheric control of the magnetosphere: conductance, Ann. Geophys., 22, 567-584, doi:10.5194/angeo-22-567-2004, 2004.

Sckopke, N.: A General Relation between the Energy of Trapped Particles and the Disturbance Field near the Earth, J. Geophys. Res., 71, 3125-3130, doi:10.1029/JZ071i013p03125, 1966. 
Shen, C., Yang, Y. Y., Rong, Z. J., Li, X., Dunlop, M., Carr, C. M., Liu, Z. X., Baker, D. N., Chen, Z. Q., Ji, Y., and Zeng, G.: Direct calculation of the ring current distribution and magnetic structure seen by Cluster during geomagnetic storms, J. Geophys. Res. Space Physics, 119, 2458-2465, doi:10.1002/2013JA019460, 2014.

Spence, H. E., Kivelson, M. G., and Walker, R. J.: Magnetospheric plasma pressure in the midnight meridian: Observations from 2.5 to 35 re, J. Geophys. Res., 94, 5264-5272, 1989.

Stern, D. P.: The motion of a proton in the equatorial magnetosphere, J. Geophys. Res., 80, 595, doi:10.1029/JA080i004p00595, 1975.

Tsyganenko, N. A.: A magnetospheric magnetic field model with a warped tail current sheet, Planet. Space Sci., 37, 5-20, 1989.

Tsyganenko, N. A.: Modeling the inner magnetosphere: The asymmetric ring current and Region 2 Birkeland currents revisited, J. Geophys. Res., 105, 27739-27754, doi:10.1029/2000JA000138, 2000.

Tsyganenko, N. A. and Sitnov, M. I.: Modeling the dynamics of the inner magnetosphere during strong geomagnetic storms, J. Geophys. Res., 110, A03208, doi:10.1029/2004JA010798, 2005.

Tsyganenko, N. A., Singer, H. J., and Kasper, J. C.: Storm-time distortion of the inner magnetosphere: How severe can it get?, J. Geophys. Res., 108, 1209, doi:10.1029/2002JA009808, 2003.

Vallat, C., Dandouras, I., Dunlop, M., Balogh, A., Lucek, E., Parks, G. K., Wilber, M., Roelof, E. C., Chanteur, G., and Rème, H.: First current density measurements in the ring current region using simultaneous multi-spacecraft CLUSTER-FGM data, Ann. Geophys., 23, 1849-1865, doi:10.5194/angeo-23-18492005, 2005.

Vasyliunas, V. M.: Mathematical models of magnetospheric convection and its coupling to the ionosphere, in: Particles and Fields in the Magnetosphere, edited by: McCormac, B. M., p. 60, D. Riedel, Hingham, Mass., 1970.
Volland, H.: A semiempirical model of large-scale magnetospheric electric fields, J. Geophys. Res., 78, 171, doi:10.1029/JA078i001p00171, 1973.

Zaharia, S., Jordanova, V. K., Thomsen, M. F., and Reeves, G. D.: Self-consistent modeling of magnetic fields and plasmas in the inner magnetosphere: Application to a geomagnetic storm, J. Geophys. Res., 111, A11S14, doi:10.1029/2006JA011619, 2006.

Zhang, J., Richardson, I. G., Webb, D. F., Gopalswamy, N., Huttunen, E., Kasper, J. C., Nitta, N. V., Poomvises, W., Thompson, B. J., Wu, C.-C., Yashiro, S., and Zhukov, A. N.: Solar and interplanetary sources of major geomagnetic storms (Dst $\leq$ $-100 \mathrm{nT}$ ) during 1996-2005, J. Geophys. Res., 112, A10102, doi:10.1029/2007JA012321, 2007a.

Zhang, J., Richardson, I. G., Webb, D. F., Gopalswamy, N., Huttunen, E., Kasper, J. C., Nitta, N. V., Poomvises, W., Thompson, B. J., Wu, C.-C., Yashiro, S., and Zhukov, A. N.: Correction to "Solar and interplanetary sources of major geomagnetic storms (Dst $\leq-100 \mathrm{nT}$ ) during 1996-2005", J. Geophys. Res., 112, A12103, doi:10.1029/2007JA012891, 2007b.

Zhang, J.-C., Wolf, R. A., Spiro, R. W., Erickson, G. M., Sazykin, S., Toffoletto, F. R., and Yang, J.: Rice Convection Model simulation of the substorm-associated injection of an observed plasma bubble into the inner magnetosphere: 2. Simulation results, J. Geophys. Res., 114, A08219, doi:10.1029/2009JA014131, 2009.

Zhang, Q.-H., Dunlop, M. W., Lockwood, M., Holme, R., Kamide, Y., Baumjohann, W., Liu, R.-Y., Yang, H.-G., Woodfield, E. E., Hu, H.-Q., Zhang, B.-C., and Liu, S.-L.: The distribution of the ring current: Cluster observations, Ann. Geophys., 29, 16551662, doi:10.5194/angeo-29-1655-2011, 2011. 